OPEN ACCESS

Edited by:

Jia Yin,

Hunan Normal University, China

Reviewed by:

Xiao Bin Zeng,

Jinan University, China

Karthik Loganathan,

Salem Microbes Pvt. Ltd., India

*Correspondence:

Xiaopeng Tang

tangxiaopeng110@126.com

Rejun Fang

fangri63@126.com

Specialty section:

This article was submitted to

Microbial Symbioses,

a section of the journal

Frontiers in Microbiology

Received: 03 June 2021

Accepted: 16 July 2021

Published: 09 August 2021

Citation:

Tang X, Liu X, Zhong J and Fang $R$ (2021) Potential Application

of Lonicera japonica Extracts in

Animal Production: From the

Perspective of Intestinal Health.

Front. Microbiol. 12:719877.

doi: 10.3389/fmicb.2021.719877

\section{Potential Application of Lonicera japonica Extracts in Animal Production: From the Perspective of Intestinal Health}

\author{
Xiaopeng Tang ${ }^{1 *}$, Xuguang Liu ${ }^{1}$, Jinfeng Zhong ${ }^{2}$ and Rejun Fang ${ }^{3 *}$ \\ 'State Engineering Technology Institute for Karst Desertfication Control, School of Karst Science, Guizhou Normal University, \\ Guiyang, China, ${ }^{2}$ Hunan Polytechnic of Environment and Biology, College of Biotechnology, Hengyang, China, ${ }^{3}$ College of \\ Animal Science and Technology, Hunan Agricultural University, Changsha, China
}

Lonicera japonica (L. japonica) extract is rich in active substances, such as phenolic acids, essential oils, flavones, saponins, and iridoids, which have a broad spectrum of antioxidant, anti-inflammatory, and anti-microbial effect. Previous studies have demonstrated that L. japonica has a good regulatory effect on animal intestinal health, which can be used as a potential antibiotic substitute product. However, previous studies about intestinal health regulation mainly focus on experimental animals or cells, like mice, rats, HMC-1 Cells, and RAW 264.7 cells. In this review, the intestinal health benefits including antioxidant, anti-inflammatory, and antimicrobial activity, and its potential application in animal production were summarized. Through this review, we can see that the effects and mechanism of $L$. japonica extract on intestinal health regulation of farm and aquatic animals are still rare and unclear. Further studies could focus on the regulatory mechanism of $L$. japonica extract on intestinal health especially the protective effects of $L$. japonica extract on oxidative injury, inflammation, and regulation of intestinal flora in farm animals and aquatic animals, thereby providing references for the rational utilization and application of $L$. japonica and its extracts in animal production.

Keywords: Lonicera japonica extract, intestinal microorganisms, intestinal immunity, intestinal health, animal production

\section{INTRODUCTION}

The animal intestinal tract is the direct place for the communication between the internal environment and the external environment, and is an important defense line for animals to maintain the homeostasis of the internal environment (Tang et al., 2016). A healthy gut is essential for the growth and development of animals. However, the intestinal epithelium homeostasis of animals is affected by numerous factors, such as bacterial infection, endotoxin challenge, weaning stress, and oxidative stress, leading to intestinal damage and intestinal barrier function dysfunction (Campbell et al., 2013; Yin et al., 2014; Zhu H. et al., 2018). Traditionally, antibiotics are generally used as growth and health promoters, which have achieved certain achievements and promoted the development of animal husbandry (Barton, 2014). However, the abuse of antibiotics in livestock and poultry feeds will destroy the intestinal 
microecological balance, and lead to the resistance of bacteria (Hashemi and Davoodi, 2011; Looft et al., 2014), which would bring serious negative effects on human health and environmental safety. Therefore, the use of antibiotics as intestinal microecological regulator is no longer popular. Exploring new antibiotic substitutes to regulate intestinal microflora and to maintain the intestinal health of animals is an urgent task in the field of animal nutrition in the post-antibiotic era.

Plant extract is a complex mixture of compounds. It has been reported to possess multiple bioactivities such as antioxidant (Liu et al., 2018), anti-inflammatory (Wu et al., 2017), antimicrobial (Kavoosi et al., 2013), and immune regulation (Boskabady et al., 2013). Plant extracts have been used for centuries in traditional medicine and as food preservatives, and more recently have been studied as possible feed additives used in animal nutrition due to their multiple biological functions (Kim et al., 2012; Yejun et al., 2019). Lonicera japonica (L. japonica) extract is extracted from $L$. japonica Thunberg, a medicine food homologous herb rich in organic acids, volatile oils, flavonoids, iridoids, and saponins (Shang et al., 2011; Fan et al., 2019; Li R. et al., 2020), which have high value of health benefits. Lonicera japonica extract is widely used in pharmacological preparations, cosmetics, food, and animal husbandry because of its diverse pharmacological effects such as antioxidant, anti-microbial, antiviral, antitoxic, antiseptic, and anti-inflammatory properties (Kang et al., 2010; Park et al., 2012; Yejun et al., 2019). The application of L. japonica extract in animal production mainly focuses on pigs (Liu W. et al., 2016), beef cattle (Yejun et al., 2019), dairy cows (Ma et al., 2020b; Zhao et al., 2020), broiler (Müştak et al., 2015), laying hens (Long et al., 2018), Penaeus monodon (Chen et al., 2013), grass carp (Meng et al., 2019), and olive flounder (Dharaneedharan et al., 2016). From the results of these studies, L. japonica extract can function as a potential alternative antibiotic in animal feeds. However, the studies of the impacts of $L$. japonica extract on the intestinal health of animals are scattered in different pieces of literature, and little research could aggregate these findings into a single review. Therefore, the objective of this study was to review the effects of $L$. japonica extract on intestinal health and summarize its application in animal production.

\section{BIOACTIVE COMPOUNDS OF L. JAPONICA EXTRACT}

Lonicera japonica, also known as Japanese honeysuckle, Jin YinHua or Ren Dong, belongs to the member of the Caprifoliaceae family, is a perennial deciduous shrub native to East Asia and spread throughout Argentina, Brazil, Mexico, Australia, New Zealand, and American (Kim et al., 2015). Traditionally, the flower bud of $L$. japonica, which has been listed in the Chinese Pharmacopeia as L. japonica Flos, is a traditional Chinese medicine that reportedly has antioxidant, anti-inflammatory, antibacterial, antiviral, antitumor, and antidiabetic properties (Liu Z. et al., 2016; Shi et al., 2016; Wang et al., 2017), which has been widely used for preventing and treating influenza, cold, fever, and infections (Kashiwada et al., 2013; Ge et al., 2018; Fang et al., 2020). Lonicera japonica extract is extracted from L. japonica, has complicated chemical composition. So far, more than 300 chemical compounds have been isolated from and identified from L. japonica, and the major compositions are phenolic acids, essential oils, flavones, saponins, and iridoids (Shang et al., 2011; Li et al., 2017, 2019; Li R. et al., 2020).

\section{Phenolic Acids}

There are more than 49 kinds of phenolic acids in L. japonica, which is mainly composed of chlorogenic acid (CGA) derivatives and cinnamic acid derivatives (Duan et al., 2018; Li et al., 2019; Li and Han, 2020; Qiu et al., 2021). A total of 27 CGA have been isolated and identified from $L$. japonica, such as CGA, neochlorogenic acid (NGC), isochlorogenic acid A, isochlorogenic acid B, isochlorogenic acid C, etc. (Iwahashi et al., 1986; Chang and Hsu, 1992; Peng et al., 2000; Lee et al., 2010; Seo et al., 2012; Yu et al., 2015; Duan et al., 2018; Li et al., 2019; Liu et al., 2020; Wang H. et al., 2020). About 16 cinnamic acid derivatives, like caffeic acid (CA), 1-O-caffeoylquinic acid, trans-cinnamic acid, trans-ferulic acid, caffeic acid methyl ester, and so on, have been isolated and identified from L. japonica (Iwahashi et al., 1986; Chang and Hsu, 1992; Choi et al., 2007; Jeong et al., 2015; Yu et al., 2015; Duan et al., 2018; Li et al., 2019). Other phenolic acids including 2,5-dihydroxybenzoic acid-5-O- $\beta$-D-glucopyranoside, vanillic acid, vanillic acid 4 -O- $\beta$-D-(6-O-benzoyl glucopyranoside), vanillic acid-4-O- $\beta$-D(6-O-benzoyl pyranoside), and protocatechuic acid (Choi et al., 2007; Lee et al., 2010; Li et al., 2019) were also identified from L. japonica. Among them, CGA and CA are the two most studied compounds in L. japonica, which have confirmed to possess potent activities of anti-inflammation, antioxidant, and antibacterial (Hsu et al., 2016; Hou et al., 2017; Li et al., 2019; Li R. et al., 2020). In particular, CGA is the most abundant phenolic acid in L. japonica, and it has been used as a marker to characterize the chemical qualities of $L$. japonica (Tzeng et al., 2014; Chen et al., 2017a; Li et al., 2019).

\section{Essential Oils}

Essential oils are one of the bioactivity components of L. japonica, which mainly composed of acids, aldehydes, alcohols, ketones, and their esters (Li et al., 2019). They exist in the aerial parts of L. japonica, flower (fresh and dry), leaves, and vines with a different content and composition (Shang et al., 2011). Vukovic et al. (2012) showed that the main constituents in the flowers fraction were (Z,Z)-farnesole (16.2\%) and linalool (11.0\%), the main constituents in the leaves fraction were hexadecanoic acid (16.0\%) and linalool (8.7\%), and the main constituents in the stems were hexadecanoic acid (31.4\%). Essential oils in L. japonica are also affected by different habitats. Du et al. (2015) identified 35 volatile constituents in L. japonica from Guangxi Zhuang Autonomous Region (China), mainly including methyl linolenate, $\mathrm{n}$-hexadecanoic acid, and $\varepsilon$-muurolene, and 18 volatile constituents in LJF from Hunan province (China), mainly including $\mathrm{n}$-hexadecanoic acid, linoleic acid, and $\alpha$-curcumene. Essential oils, the most kinds of bioactivity 
component in L. japonica, have important pharmacological effects, and have been used in cosmetics, spices, and other industries widely (Wang L. et al., 2016). It also suggests that the characterization of the volatile compounds could be used as an indicator of the identity and the quality of L. japonica (Cai et al., 2013).

\section{Flavonoids}

Flavonoids are secondary metabolites and widely exist in natural plants including L. japonica (Han et al., 2016; Li R. et al., 2020; Liu et al., 2020), a group of natural or synthetic compounds containing parent cyclic structures and their O- and C-glycosylated derivatives with structural diversity (Rauter et al., 2018). Up to now, about 52 flavonoids have been isolated from L. japonica, which is mainly composed of flavonols (12 kinds) and flavones (36 kinds), and most of them are glycosides (Li et al., 2019). The flavonols mainly include rutin, quercetin, isoquercitrin, astragalin, Quercetin 3-O-hexoside, and so on (Chang and Hsu, 1992; Choi et al., 2007; Lee et al., 2010; Seo et al., 2012; Ge et al., 2019). The main flavones including cynaroside, luteolin, chrysoeriol 7-O-neohesperidoside, chrysoeriol 7-O-glucoside, lonicerin, tricin, etc. (Choi et al., 2007; Lee et al., 2010; Ge et al., 2019; Fang et al., 2020). Other flavonoids including one flavonolignan (hydnocarpin), one flavanone (eriodictyol) and three biflavonoids [3'-O-methyl loniflavone (5,5",7,7"-tetrahydroxy 3'-methoxy4',4'"-biflavonyl ether), loniflavone (5,5",7,7",30-pentahydroxy 4',4"'-biflavonyl ether) and (5,7,8,4'-tetrahydroxyflavone)-3'-4-(5,7-dihydroxyflavone)] were also have been isolated and identified from L. japonica (Kumar et al., 2005; Ge et al., 2018; Li et al., 2019). According to modern pharmacological research, flavonoids extracted from L. japonica has health benefits for the prevention of cancer, diabetes, cardiovascular disease, liver injury, and cerebrovascular disease (Han et al., 2016; Ge et al., 2018; Wan H. et al., 2019).

\section{Saponins}

Most of saponins from L. japonica belong to the oleanane type and hederagenin type (Shang et al., 2011). Saponins in L. japonica were first studied by Kawai et al. (1988), and 15 chemical compounds were found. So far, about 30 saponins, such as $\alpha$-Hederin, Loniceroside A-E have been isolated and identified from L. japonica (Kawai et al., 1988; Son et al., 1994; Choi et al., 2007; Lin et al., 2008; Qi et al., 2009; Shang et al., 2011; Kuroda et al., 2014; Yu et al., 2015; Wang L. et al., 2016; Li et al., 2019). Studies showed that saponins from L. japonica have anti-inflammatory activities in vitro and in vivo (Lee et al., 1995; Kwak et al., 2003; Li et al., 2017; Ge et al., 2019).

\section{Iridoids}

Iridoids are the most abundant compounds in L. japonica, which mostly presenting as glycosides (Wang L. et al., 2016; Li et al., 2019). So far, more than 92 iridoids, like loganin, sweroside, secologanoside, ethyl secologanoside, centauroside etc., have been isolated from L. japonica (Kakuda et al., 2000; Yu et al., 2011, 2013; Zheng et al., 2012; Kashiwada et al., 2013; Liu et al., 2015, 2020; Ge et al., 2019; Yang R. et al., 2020;
Qiu et al., 2021). Studies showed that these iridoids have antiinflammatory (Song et al., 2008; Yu et al., 2011; Qiu et al., 2021) and antiviral activities (Kashiwada et al., 2013; Yu et al., 2013) in vitro and in vivo.

\section{Others}

Other chemical components except for phenolic acids, essential oils, flavonoids, saponins, and iridoids have also been isolated from L. japonica. Zhao et al. (2018) had identified 13 trace elements ( $\mathrm{Mg}, \mathrm{Cr}, \mathrm{Mn}, \mathrm{Fe}, \mathrm{Ni}, \mathrm{Cu}, \mathrm{Zn}, \mathrm{As}, \mathrm{Se}, \mathrm{Mo}, \mathrm{Cd}, \mathrm{Hg}$, and $\mathrm{Pb}$ ) with inductively coupled plasma mass-spectrometry (ICP-MS) and high-performance liquid chromatographyphotodiode array (HPLC-PDA) method. Cai et al. (2019, 2021) had identified 13 amino acids (Alanine, Serine, Proline, Valine, Threonine, Isoleucine, Leucine, Aspartic acid, Glutamate, Lysine, Histidine, Phenylalanine, and Arginine) and four nucleosides (Cytidine, Uridine, Adenosine, and Inosine) in L. japonica.

\section{LONICERA JAPONICA (EXTRACTS) AND INTESTINAL ANTIOXIDANT}

In addition to its medicinal uses, L. japonica is also widely used in healthy foods and cosmetics in the world because of its health benefits (Seo et al., 2012; Fang et al., 2020; Zhang T. et al., 2020). Modern pharmacological researches have demonstrated that L. japonica extract has a variety of biological activities, which the antioxidant activity is an important biological property of great interest (Hsu et al., 2016; Wan H. et al., 2019; Zhang T. et al., 2020). Antioxidant activity of L. japonica was mainly related to its abundant polyphenols (Lee et al., 2019) and polysaccharides (Zhou et al., 2020).

\section{Antioxidant Activity of Polyphenols}

The antioxidative property of $L$. japonica is mainly attributed to the specific chemical structure of polyphenols, a widespread group of secondary metabolites that include various phenolic acids and flavonoids, which have a common character of having at least one aromatic ring substituted with one or more hydroxyl groups (Kong et al., 2017; Fan et al., 2019). Lee et al. (2019) who reported that the antioxidant activities of L. japonica were positively correlated with total phenolic, total flavonoid, CGA, CA, and quercetin contents, and Kong et al. (2017) who reported that antioxidative activity of $L$. japonica presented a significant positive correlation with the content of CGA, cynaroside, rutin, and hyperoside can demonstrate this conclusion. Figure 1 presented the main phenolic acids (GCA, CA, and NGA) and flavonoids (luteolin 7-galactoside, quercetin, and luteolin) in L. japonica. It showed that all these compounds contain an aromatic nucleus and hydroxyl group, which is related to their strong antioxidant capacity (Choi et al., 2007; Guo et al., 2014; Hsu et al., 2016).

The ability to scavenge free radicals may play an important role in preventing some diseases caused by free radicals (Gheisar and Kim, 2018). Normally, 1,1-diphenyl-2-picrylhydrazyl (DPPH) scavenging activity assay, 2,2'-azino-bis (3-ethylbenzothiazoline6-sulfonic) acid (ABTS) scavenging activity assay, superoxide 


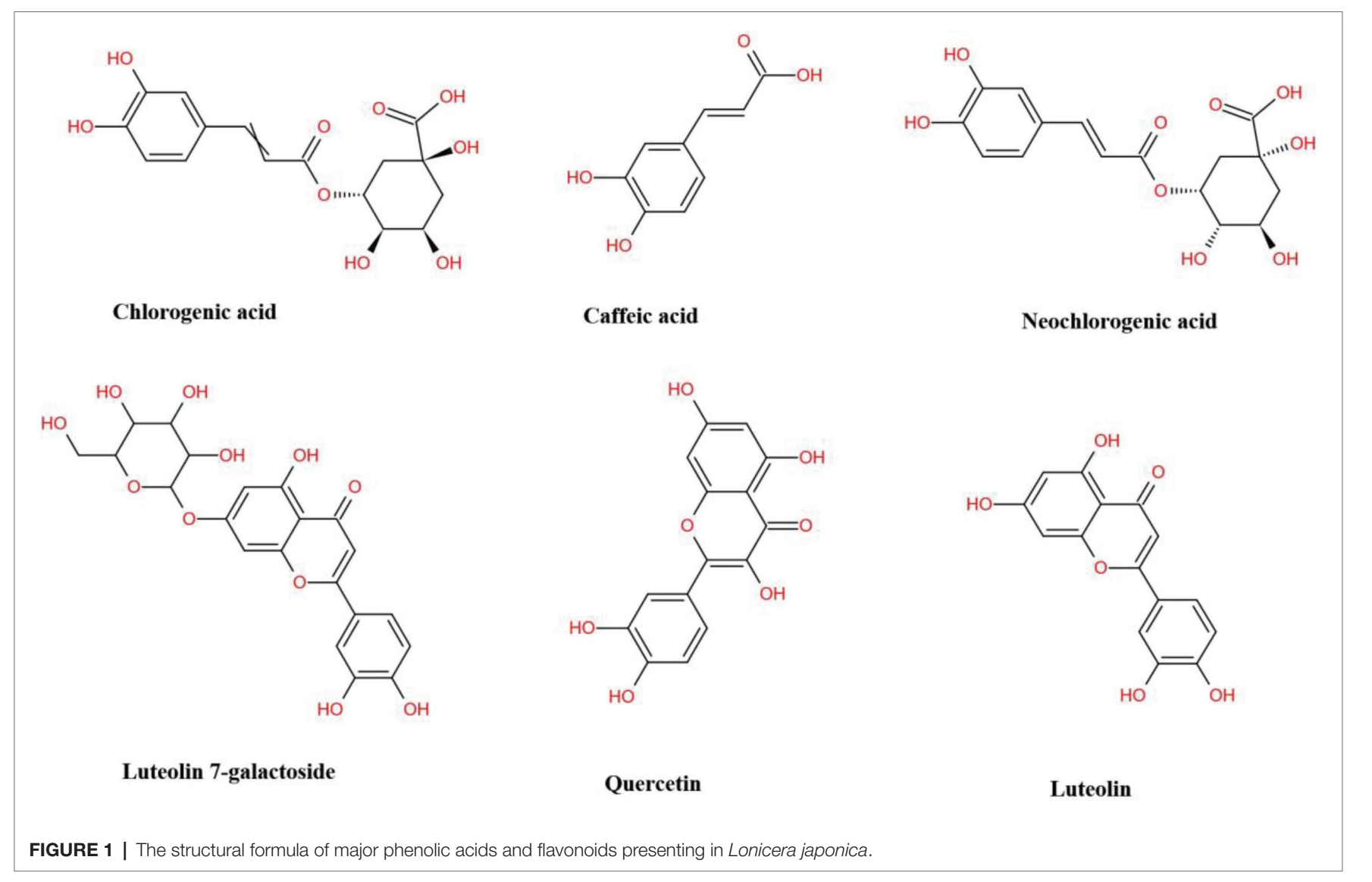

radical scavenging activity assay, ferric-reducing antioxidant power (FRAP) assay, and reducing power (RP) assay are the most frequently used to evaluate the antioxidant activity of plant extracts (Lee et al., 2011, 2019; Kong et al., 2017; Zhang T. et al., 2020). DPPH radical scavenging activity and ABTS radical scavenging activity reflect the ability of hydrogen-donating antioxidants and electron transfer to scavenge DPPH and $\mathrm{ABTS}^{+}$ radicals (Lee et al., 2019). Superoxide radical scavenging activity denotes the ability to remove free radicals, such as peroxyl, alkoxyl, hydroxyl, and nitric oxide, which formed from superoxide anions through the Fenton reaction, lipid oxidation, or nitric oxidation (Hsu et al., 2016). FRAP and RP assays represent their ability to reduce the of ferric $\left(\mathrm{Fe}^{3+}\right)$ form to the ferrous $\left(\mathrm{Fe}^{2+}\right)$ form (Seo et al., 2012; Lee et al., 2019). Chaowuttikul et al. (2017) reported that the ethanolic extract of $L$. japonica showed DPPH and nitric oxide scavenging activities as well as RP property. Lee et al. (2019) showed that DPPH and ABTS radical scavenging activity of $L$. japonica were significantly increased during $60 \mathrm{~min}$ of heating and were retained for $90 \mathrm{~min}$.

\section{Antioxidant Activity of Polysaccharides}

Polysaccharides are a kind of natural polymer linked by aldose or ketose through glycosidic bonds (Zhou et al., 2018a, 2021). Previous studies have found that polysaccharides extracted from plants can relieve oxidative stress through exerting their antioxidation potentials (Surin et al., 2018; Zhou et al., 2020). Polysaccharide is one of the main active ingredients of L. japonica, which have been isolated and identified in previous studies (Zhou et al., 2018a, 2020; Liu et al., 2019; Zhang T. et al., 2020). In vitro study showed that polysaccharide extracts from L. japonica exhibited obvious DPPH-scavenging activity, $\mathrm{ABTS}^{+}$scavenging activity, hydroxyl radical-scavenging activity, superoxide radical-scavenging activity, and excellent inhibitory activity on erythrocyte hemolysis induced by $\mathrm{H}_{2} \mathrm{O}_{2}$ (Zhang $\mathrm{T}$. et al., 2020). Polysaccharide extracts from L. japonica could protect cardiomyocytes of mice injured by hydrogen peroxide via increasing the activities of catalase (CAT), glutathione peroxidase (GSH-Px), and superoxide dismutase (SOD), and decreasing ROS production (Zhou et al., 2020). In vivo study showed that crude polysaccharides extracted from L. japonica could alleviate the oxidative damage of liver in streptozotocin (STZ)-induced diabetic rats by decreasing alanine aminotransferase (ALT), aspartate aminotransferase (AST), and gamma-glutamyl transpeptidase (GGT) in serum, and improving levels of CAT, SOD, and GSH in liver (Wang et al., 2017). It reveals that the polysaccharides play an important role in the antioxidant function of L. japonica.

\section{Potential Intestinal Antioxidant Effects of L. japonica (Extract)}

Reactive oxygen species (ROS) are generated along with the process of cell respiration and normal metabolism continuously, and mitochondrion is the primary source of the majority of ROS in organisms (Wang Y. et al., 2020; Yan Z. et al., 2020). 
ROS includes free radical ROS and non-radical ROS. Free radical ROS mainly include superoxide anion free radicals $\left(\mathrm{O}_{2}^{-}\right)$, hydroxyl radical $\left(\cdot \mathrm{OH}^{-}\right)$, peroxyl radical ( $\left.\mathrm{ROO}\right)$, and alkoxyl radical (RO), and non-radical ROS mainly consist of hydrogen peroxide $\left(\mathrm{H}_{2} \mathrm{O}_{2}\right)$, oxygen $\left(\mathrm{O}_{2}\right)$, ozone $\left(\mathrm{O}_{3}\right)$, hypochlorous acid (HOCL), hypobromous acid (HOBr), chloramines (RNHCL), and organic hydroperoxides (ROOH; Wang Y. et al., 2020). Under normal physiological conditions, ROS can act as signaling molecules involved in cell growth and cellular adaptive responses (Lum and Roebuck, 2001). However, in commercial animal production, animals often suffer from bacterial infection (Zhang X. et al., 2020), endotoxin challenge (Chen et al., 2021), mycotoxin challenge ( $\mathrm{Xu}$ et al., 2020), and weaning stress (Zhou et al., 2018b), which may induce a large number of ROS. When the body cannot remove these ROS in time, oxidative stress injury occurs (Campbell et al., 2013; Yin et al., 2014; Zhu H. et al., 2018; Saracila et al., 2021). Numerous studies have demonstrated that oxidative stress is associated with many pathological conditions, including intestinal barrier dysfunction and various digestive tract diseases (Almenier et al., 2012; Navarro-Yepes et al., 2014; Cao et al., 2018; Tang et al., 2018b;
Chen et al., 2020, 2021). Thus, alleviating the negative effects of oxidative stress damage is crucial for the development of the animal husbandry.

The latest research progress of antioxidant activity of L. japonica has been summarized in Table 1. These studies suggested that $L$. japonica might be potential natural antioxidants and beneficial chemopreventive agent, which can be inferred that the extract of $L$. japonica may have a protective effect on intestinal oxidative damage of animals. However, the direct evidence of the protective effects $L$. japonica on intestinal oxidative damage is still lack. Therefore, further studies are needed to confirm whether L. japonica have a regulating effect on the intestinal oxidative damage of animals including farm animals and aquatic animals.

\section{LONICERA JAPONICA (EXTRACTS) AND INTESTINAL INFLAMMATION}

The intestine is different from the other organs of animal because it is not only the main part of animal nutrition

TABLE 1 | Antioxidant activity of Lonicera japonica in vitro and in vivo.

\begin{tabular}{|c|c|c|c|}
\hline Animal/Cell models & Active compounds & Main results & References \\
\hline LPS-induced RAW264.7 cells & Ethanolic extract & $\begin{array}{l}\text { Significantly decreased the ROS level in the stimulated } \\
\text { macrophage cells }\end{array}$ & Yoo et al., 2008 \\
\hline 6-OHDA-induced SH-SY5Y cells & Ethyl acetate extract & $\begin{array}{l}\text { Significantly decrease ROS and increase the GSH level, SOD } \\
\text { activity, and CAT activity in 6-OHDA-induced SH-SY5Y cells }\end{array}$ & Kwon et al., 2012 \\
\hline $\mathrm{H}_{2} \mathrm{O}_{2}$-induced rat cardiomyocytes & Caffeoylquinic acids & $\begin{array}{l}\text { Significantly attenuated hypoxia-induced ROS generation and } \\
\text { reduced the ratio of GSSG/GS total }\end{array}$ & Wang C. et al., 20 \\
\hline High-fat-induced hyperlipidemia rats & Water extracts & $\begin{array}{l}\text { Could suppress the oxidative stress by increasing serum SOD, } \\
\text { GSH-Px, and reducing MDA concentration in hyperlipidemia rats }\end{array}$ & Wang F. et al., 201 \\
\hline $\begin{array}{l}\text { Streptozotocin (STZ)-inducd diabetic } \\
\text { rats }\end{array}$ & Polysaccharide & $\begin{array}{l}\text { The oxidant stress in liver was restored by increasing the levels } \\
\text { of CAT, SOD, and GSH in liver }\end{array}$ & Wang et al., 2017 \\
\hline $\mathrm{H}_{2} \mathrm{O}_{2}$-induced HepG 2 cells & Flavonoids & Dose-dependent increased CAT and SOD activity & Tzeng et al., 2014 \\
\hline $\mathrm{H}_{2} \mathrm{O}_{2}$-induced RAW264.7 cells & Flavonoids & $\begin{array}{l}\text { Dose-dependent reduced MDA content in cells and culture } \\
\text { supernatant, improve SOD activity and GSH content, and } \\
\text { increase intracellular lactate dehydrogenase activity. }\end{array}$ & Luo et al., 2018 \\
\hline $\mathrm{H}_{2} \mathrm{O}_{2}$-induced hepatoma cells & Japoflavone D & $\begin{array}{l}\text { Treatment of Japoflavone D suppressed the activation of ERK } \\
\text { and mTOR and activated the KEAP1/NRF2/ARE signaling axis }\end{array}$ & Wan H. et al., 201 \\
\hline Gastritis and peptic ulcer rats & BST-104 & $\begin{array}{l}\text { BST-104 treatment increased antioxidant activities (higher levels } \\
\text { of CAT, SOD, and GSH/GSSG, and lower MDA levels) }\end{array}$ & Bang et al., 2019 \\
\hline $\mathrm{H}_{2} \mathrm{O}_{2}$-induced HepG2 cells & 4,5-CQME & $\begin{array}{l}\text { Reduced ROS and MDA levels and rescued GSH depletion; 4,5- } \\
\text { CQME regulated the Keap1/Nrf2 signaling pathway and enhanced } \\
\text { both the mRNA and protein expressions of } \mathrm{HO}-1 \text { and } \mathrm{NQO1}\end{array}$ & Xiao et al., 2020 \\
\hline $\mathrm{H}_{2} \mathrm{O}_{2}$-induced mice cardiomyocytes & Polysaccharide & $\begin{array}{l}\text { Significantly increased the activities CAT, GSH-Px, and SOD, } \\
\text { and decrease ROS production }\end{array}$ & Zhou et al., 2020 \\
\hline Beef cattle under heat stress & Not mentioned & $\begin{array}{l}\text { Serum SOD, GSH-Px, and T-AOC was increased, and serum } \\
\text { MDA was decreased }\end{array}$ & Fu et al., 2016 \\
\hline Dairy cows & Not mentioned & $\begin{array}{l}\text { Quadratically increased the activity of GSH-Px and T-AOC in } \\
\text { serum but decreased concentration of MDA }\end{array}$ & Ma et al., 2020a \\
\hline Dairy cows & Not mentioned & $\begin{array}{l}\text { Lonicera japonica supplementation decreased the } \\
\text { concentrations of reactive ROM, meanwhile increased the } \\
\text { T-AOC and SOD concentrations in blood }\end{array}$ & Zhao et al., 2020 \\
\hline
\end{tabular}

BST-104, a water extract of L. japonica; LPS, lipopolysaccharide; CAT, catalase; GSH-Px, glutathion peroxidase; SOD, superoxide dismutase; T-AOC, total antioxidant capacity; MDA, malonaldehyde; ROM, reactive oxygen metabolites; 6-OHDA, 6-hydroxydopamine; rCMEC, rat cardiac microvascular endothelial cells; ROS, reactive oxygen species; 4,5CQME, 4,5-di-O-caffeoylquinic acid methyl ester; Keap1, kelch-like ECH-associated protein 1; Nrf2, nuclear factor erythroid 2-related factor 2; ARE, antioxidant response elements; HO-1, heme oxygenase; NQO1, quinone oxidoreductase; ERK, extracellular signal-related kinases; and mTOR, mammalian target of rapamycin protein. 
digestion and absorption, but also consists of a physical and immunological protective barrier against foreign antigens and pathogens from the external environment into the circulation system (Tang et al., 2016, 2018b, 2021; Curciarello et al., 2019). Optimum intestinal health is of prime importance to animal growth as well as animal health. Disruption of the intestinal epithelial homeostasis has been reported to increase intestinal permeability, which can cause numerous gastrointestinal diseases (Miner-Williams and Moughan, 2016; Tang et al., 2019; Peng et al., 2020; Tang and Xiong, 2021). Lonicera japonica extract has a significant effect on the intestinal health regulation of animals due to its various biological activities including antiinflammatory activity (Kang et al., 2010; Han et al., 2016; Zhou et al., 2021).

\section{Anti-inflammatory Activity of $L$. japonica (Extracts)}

Inflammation is a normal protective response induced by tissue injury or infection. It has been proved that $L$. japonica presents significant anti-inflammatory effects in vitro and in vivo (Jiang et al., 2014; Li R. et al., 2020; Zhou et al., 2021). As we know, proinflammatory cytokines, such as tumor necrosis factor $\alpha$ (TNF- $\alpha$ ), interleukin $1 \beta$ (IL- $1 \beta)$, and IL- 6 contribute to inflammatory injury and triggers an inflammatory cascade (Bang et al., 2019; Li R. et al., 2020). Kang et al. (2010) showed that L. japonica extract could suppress inflammatory mediators, such as IL6, IL- 8 , and TNF- $\alpha$ release by blocking nuclear factor- $\kappa \mathrm{B}(\mathrm{NF}-\kappa \mathrm{B})$ and mitogen-activated protein kinase (MAPKs) activation pathways in HMC-1 Cells. Su et al. (2021) showed that ethanol extract of L. japonica caulis significantly inhibit the expression of pro-inflammatory factors such as TNF- $\alpha$, IL- $1 \beta$, IL- 6 , and interferon $\gamma$ (IFN- $\gamma$ ) in mice. The study Li R. et al. (2020) suggested that the flower buds, leaves, and stems of L. japonica extracts showed a cytoprotective effect on lipopolysaccharide (LPS) stimulated RAW 264.7 macrophages by suppressing proinflammatory cytokines including TNF- $\alpha$, IL-1 $\beta$, and IL- 6 production. Bang et al. (2019) showed that the anti-inflammatory effects of BST-104 (a water extract of L. japonica) were attributed to reduced levels of proinflammatory cytokines, such as TNF- $\alpha$, IL- $1 \beta$, and IL- 6 in gastric mucosal tissues. All of these researches suggest that L. japonica is a good anti-inflammatory agent for treating inflammatory disorders.

\section{Lonicera japonica (Extracts) Inhibits Intestinal Inflammation}

The intestinal tract is the largest immune organ in the body and acts as the first line of defense against infection and a barrier that prevents commensal bacteria from penetrating the intestinal epithelium (Tang et al., 2016; Clavijo and Flórez, 2018; Qamar et al., 2021). The gut immune system comprises mucosal layer, epithelial cells, antibacterial peptides, immunoglobulins, and cytokines (Yitbarek et al., 2019; Qamar et al., 2021). Previous studies had demonstrated that L. japonica can promote intestinal immune function and has a preventive effect on intestinal inflammation (Park et al., 2012;
Yang X. et al., 2020). Yang X. et al. (2020) showed that the treatment of the alcohol extract of $L$. japonica to mice significantly increased intestinal sIgA content. Zhou et al. (2021) showed that with the supplementation of $L$. japonica polysaccharides, the content of immunoglobulin A ( $\operatorname{Ig} \mathrm{A})$ secreted from the intestine was significantly higher than that of dextran sulfate sodium (DSS)-induced ulcerative colitis mice. sIgA, an immunoglobulin secreted by plasma cells of the intestinal mucosa, is a major effector of the intestinal mucosal immunity, which acts as the first line of defense in the intestinal mucosa that neutralizes pathogens in the intestinal mucosa and plays an important role in local anti-infection of the body (SalernoGoncalves et al., 2016; Zhou et al., 2021). These studies indicated that prompting the secretion of $\operatorname{sgA}$ is one of the ways to enhance the immune ability of the intestine by L. japonica (Yang X. et al., 2020; Zhou et al., 2021). In addition to promoting the secretion of $\operatorname{sigA}, L$. japonica can also play the role of intestinal immune function by regulating the secretion of intestinal mucosal cytokines (Park et al., 2012; Zhou et al., 2018a). Lee et al. (2011) showed that buthanol (BuOH) extracts of L. japonica inhibited the synthesis of IL-6 in a LPS-stimulated colonic epithelial cell line (HT-29 cell) in vitro and a DSS-induced ulcerative colitis mouse in vivo. Park et al. (2012) showed that $L$. japonica inhibited the cytokines including TNF- $\alpha$, IL-1 $\beta$, IL-6, IFN- $\gamma$, IL-12, and IL-17 in DSS-induced ulcerative colitis mice. In an immunosuppressed mice model, the researchers found that polysaccharide extracts from L. japonica could restore the levels of serum cytokines IL-2, TNF- $\alpha$, and IFN- $\gamma$ level in cyclophosphamide-induced mice, which indicated that L. japonica can be used as a potential immunomodulatory agent (Zhou et al., 2018a). Through these studies, we can speculate that L. japonica extract may also had regulation on intestinal immune function and intestinal inflammation of farm and aquatic animals, which of course needs further researches to demonstrate it.

\section{LONICERA JAPONICA (EXTRACTS) AND GUT MICROBIOTA}

\section{Gut Microbiota and Intestinal Health}

The gastrointestinal tract, the largest organ in the animal body, provides a broad colonization surface for the flora. Thousands of bacteria colonize the entire gut, which directly interrelates with the host and contributes to the regulation of the host intestinal barrier function and homeostasis (Chen et al., 2017b; Wan M. et al., 2019; Hayashi et al., 2021; Qamar et al., 2021). The gut barrier is central to the maintenance of gut homeostasis and breakdown of the barrier is involved in a wide variety of clinical conditions (Alam and Neish, 2018). Gut microbiota plays a vital role in host health, which is thought to tightly associate with the intestinal barrier function including physical barrier, chemical barrier, immune barrier, and microbial barrier (Figure 2; Guevarra et al., 2018; Makki et al., 2018). First of all, the intestinal microbial barrier is composed of many normal intestinal floras, which play an important role in intestinal microecological balance regulation, 


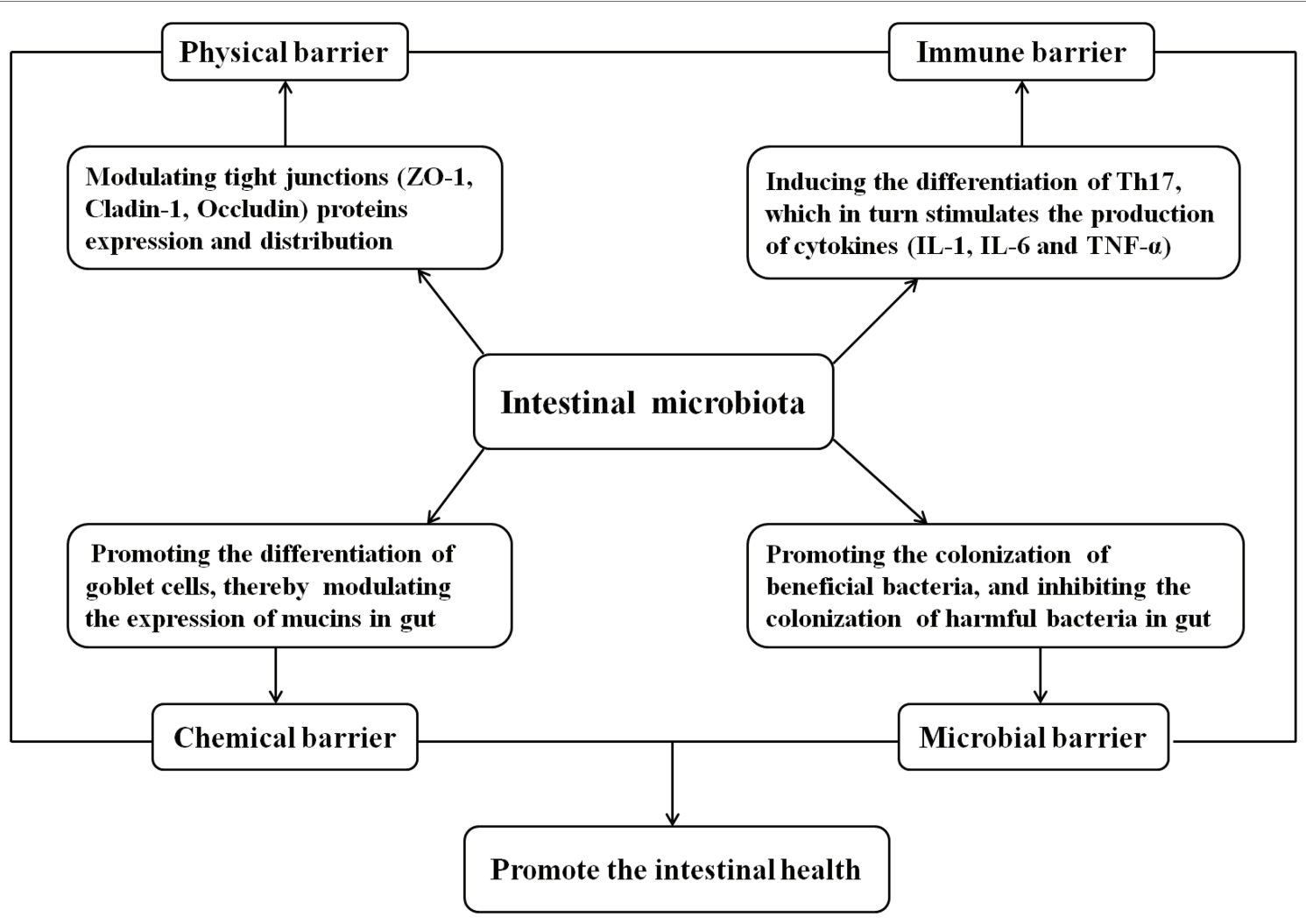

FIGURE 2 | Relationship between gut microbiota and intestinal health.

and the imbalance of intestinal floras may result in intestinal dysfunction (Tan et al., 2015; Li X. et al., 2020). Second, intestinal commensal segmented filamentous bacteria can induce the differentiation of $\mathrm{T}$ helper 17 (Th17) in the lamina prima, which in turn stimulates the production of cytokines, IL-1, IL- 6 , and TNF- $\alpha$ by a variety of cells (Goto et al., 2014; Villena et al., 2014). Metabolites such as short-chain fatty acids (SCFA) produced by the gut bacteria are considered as key molecular intermediates between the microbiota and its host (Beaumont et al., 2020). SCFA can induce the proliferation and differentiation of Treg, thus activating the intestinal immune system and playing the function of immune barrier (Horai et al., 2017). Third, the intestinal floras can influence the intestinal physical barrier by modulating tight junction (TJ) proteins expression and distribution (Zhu L. et al., 2018; Li X. et al., 2020). For example, Hu et al. (2020) reported that piglets receiving protocatechuic acid promoted the expression of ZO-1 and Claudin-1 in the intestinal mucosa by increasing the abundance of the beneficial bacteria Roseburia in the intestinal tract thus maintaining the function of the intestinal barrier. Finally, the intestinal floras can also influence the intestinal chemical barrier by promoting the differentiation of goblet cells, thereby modulating the expression of mucins (MUCs), a family of highly glycosylated protein that are secreted by specialize cells in the gut, which is the main component of intestinal mucus (Sicard et al., 2017). In a word, intestinal flora is closely related to intestinal health.

\section{Lonicera japonica (Extracts) Modulates Intestinal Micobiota}

Modern pharmacological research has confirmed the strong antimicrobial activity of $L$. japonica in vivo and in vitro (Rhee and Lee, 2011; Xiong et al., 2013; Yang et al., 2016; Minami and Makino, 2020; Yan L. et al., 2020). In vitro study showed that $L$. japonica has antimicrobial effects such as Bacteroides fragilis, Bacteroides ovatus, Clostridium difficile, Clostridium perfringenes, Propionebacterium acnes, Staphylococcus aureus, Shigella, Salmonella, and Escherichia coli (E. coli; Rhee and Lee, 2011; Xiong et al., 2013; Yang et al., 2016, 2018; Yan L. et al., 2020). In vivo study showed that $L$. japonica could significantly promote the colonization of beneficial bacteria and inhibit the reproduction of harmful bacteria (Minami and Makino, 2020; Yang X. et al., 2020). Wang et al. (2014) showed that unfermented or fermented $L$. japonica both can significant alteration of the distribution of intestinal flora, especially affecting the population of Akkermansia spp. and Bacteroidetes/Firmicutes ratio in obesity rats, which play an essential role in high fat diet or LPS induced enhancement in gut permeability, development of endotoximia, and inflammation. Minami and Makino (2020) showed that L. japonica significantly increased the survival rate and decreased Citrobacter rodentium (C. rodentium) colonization in the large intestine of mice. Citrobacter rodentium is a mucosal pathogen of murine, which has long used as a model to elucidate the molecular and cellular pathogenesis of infection with enteropathogenic E. coli and 
enterohaemorrhagic E. coli, two clinically important human gastrointestinal pathogens (Collins et al., 2014; Bouladoux et al., 2017; Mullineaux-Sanders et al., 2019). Yang X. et al. (2020) showed that the water extract of L. japonica and alcohol extract of L. japonica did not damage the intestinal structure, and both of them could promote the growth of beneficial bacteria Lactobacillus and inhibit the growth of potential pathogenic bacteria E. coli. Lactobacillus is a predominant indigenous bacterial genus found in the human and animal gastrointestinal tract, and species of this genus like Lactobacillus plantarum (L. plantarum; Wang et al., 2018), Lactobacillus casei (Eun et al., 2011), Lactobacillus rhamnosus (Villena et al., 2014), and Lactobacillus reuteri (Yang et al., 2015) etc., are commonly used as probiotics, which can affect transepithelial electrical resistance (TER) and epithelial permeability, modulate TJ proteins distribution, and enhance the immune function. Escherichia coli strains are important pathogens that cause diverse diseases in humans and animals, which is a major challenge for intestinal health (Dautzenberg et al., 2016; Stromberg et al., 2017; Desvaux et al., 2020). Therefore, it reveals that L. japonica has a good regulatory effect on animal intestinal microbiota, thus promoting the intestinal health of animals. However, the studies of $L$. japonica extract on intestinal microbiota of farm and aquatic animals are still lack, which perhaps is a good research direction in the future.

\section{APPLICATION OF L. JAPONICA IN ANIMAL PRODUCTION}

Various herbs and their extracts have been used as feed additives due to their anti-oxidative effect, anti-inflammatory activity, anti-microbial effect, and growth-promoting effect (Windisch et al., 2008; Hanczakowska et al., 2015; Lei et al., 2018; Lin et al., 2020). Among them, L. japonica (extract) was widely investigated in animal husbandry because of its diverse pharmacological effects such as antioxidant, anti-microbial, antiviral, antitoxic, antiseptic, and anti-inflammatory properties (Kang et al., 2010; Park et al., 2012; Wang et al., 2014; Li R. et al., 2020). Table 2 summarized the application of L. japonica (extract) in animal production in recently years. It showed that these studies mainly focus on pigs (Liu W. et al., 2016), beef cattle ( $\mathrm{Fu}$ et al., 2016; Yejun et al., 2019), dairy cows (Ma et al., 2020a,b; Zhao et al., 2020), broiler (Müştak et al., 2015), laying hens (Long et al., 2018), Penaeus monodon (Chen et al., 2013), grass carp (Meng et al., 2019), and olive flounder (Dharaneedharan et al., 2016).

Studies on beef cattle showed that L. japonica extract can effectively alleviate heat stress, improve antioxidant function, and have a good repair effect on skeletal muscle fiber structure damage of beef cattle (Song et al., 2015; Fu et al., 2016). Moreover, in vitro studies showed that L. japonica extract could regulate rumen fermentation and reduce methane production by inhibiting the growth of methanogenic bacteria (Huang et al., 2019; Yejun et al., 2019). Studies on dairy cows showed that dietary supplementation of $L$. japonica extract could relieve heat stress of dairy cows by improving immune and antioxidant capacity (Ma et al., 2020a,b; Gao et al., 2021), enhancing antiinflammatory activity (Zhao et al., 2020). Meanwhile, L. japonica extract can improve rumen microbial diversity and improve rumen fermentation capacity (Tang et al., 2018a). In pig production, herbal extract mixture (HEM) may have a better application effect (Liu W. et al., 2016; Wang M. et al., 2020). For instance, Liu W. et al. (2016) indicated that dietary supplementation with a mixture of 55\% Scutellaria baicalensis extract and $25 \%$ L. japonica extract administration could improve growth performance and nutrient digestibility, decrease serum cortisol levels, as well as benefit the meat quality in finishing pigs, and Wang Y. et al. (2020) showed that dietary supplementation with $1,000 \mathrm{mg} / \mathrm{kg}$ a mixture extract of goldenand-silver honeysuckle (L. japonica Thunb.), huangqi (Astragalus menbranaceus), duzhong leaves (Eucommia folium), and dangshen (Codonopsis pilosula) had beneficial effects on intestinal morphology modulation and the mRNA expression of nutrients transporters of pigs. For broilers, dietary supplementation with L. japonica extract could increase weight gain, blood cells, antioxidant activity, and meat quality of broilers (Park et al., 2014), while did not affect the proximate composition of the breast meat, but could increase the antioxidative potential and overall preference of breast meat during cold storage (Jang et al., 2008). Drinking water containing GCA extracted from L. japonica can effectively increase the body weight of broilers and reduce Mycoplasma gallisepticum infection of broilers (Müştak et al., 2015). Studies on laying hens showed that dietary supplementation with L. japonica extract (Long et al., 2018) or HEM containing L. japonica extract (Liu and Kim, 2017) could improve laying performance, eggshell strength, egg quality, and shelf life in laying hens. For aquatic animals, dietary supplementation with $L$. japonica could improve the growth performance, health condition and survival rate of Penaeus monodon (Chen et al., 2013), and could effectively improve the lipid metabolism and ameliorate the lipid deposition of grass carp (Meng et al., 2019). Flounder fish fed with 0.025 , $0.05,0.1,0.2$, and $0.4 \%$ L. japonica leaf powder for 4 weeks showed significantly increased respiratory burst, lysozyme, phagocytic activity, immune function, and antioxidant activity (Dharaneedharan et al., 2016).

\section{CONCLUSION}

Intestinal health determines the health status of animals. To regulate intestinal health is always been an important issue in the post-antibiotic era of animal husbandry. As a kind of natural plant extract, L. japonica extract is rich in phenolic acids, essential oils, flavonoids, iridoids, and saponins, which has a good regulating effect on the intestinal health of animals, and is an ideal product of antibiotics substitution. According to the published literature, although the application of L. japonica extract in animal production has been reported, it mainly focuses on the regulation of animal production performance, meat quality, egg quality, rumen fermentation capacity, and anti-heat stress, etc. In animal production, the effects of L. japonica extract on intestinal health may be related to its 
TABLE 2 | Application of L. japonica in animal production.

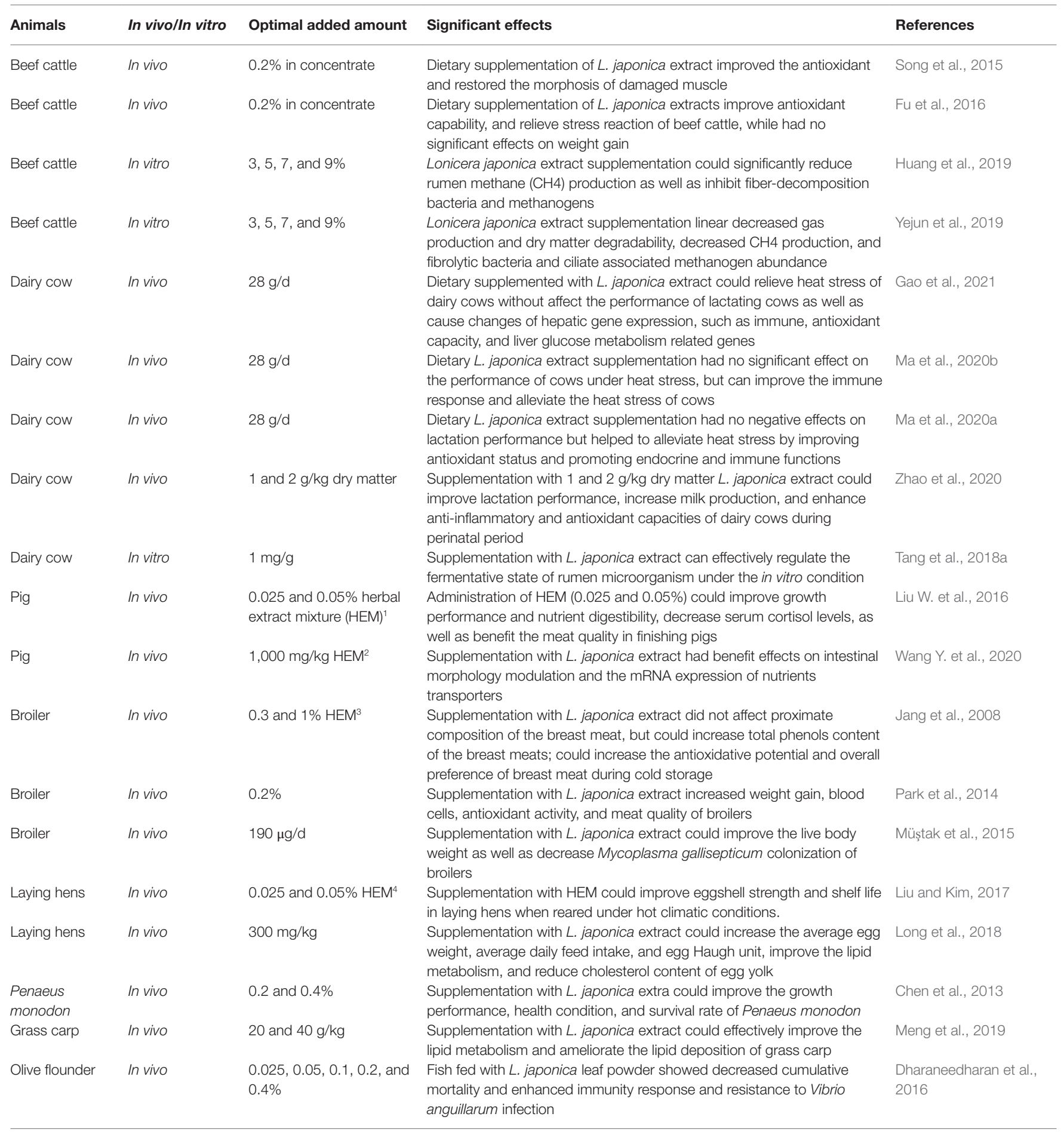

${ }^{1} A$ mixture of 55\% Scutellaria baicalensis powder extract, 25\% L. japonica powder extract, and 20\% carrier (wheat bran).

${ }^{2}$ A mixture extract of golden-and-silver honeysuckle (L. japonica Thunb.), huangqi (Astragalus menbranaceus), duzhong leaves (Eucommia folium), and dangshen (Codonopsis pilosula).

${ }^{3} A$ mixture of mulberry leaf, Japanese honeysuckle, and goldthread at a ratio of 48.5:48.5:3.0.

${ }^{4} \mathrm{~A}$ mixture of 55\% S. baicalensis powder extract, 25\% L. japonica powder extract, and $20 \%$ carrier (wheat bran).

antioxidant, anti-inflammatory, and antimicrobial activities. Although previous studies had demonstrated that about L. japonica has a good regulatory effect on animal intestinal health, but mainly focus on experimental animals or cells, like mice, rats, HMC-1 Cells, and RAW 264.7 cells, the studies of L. japonica extract on intestinal health regulation of farm and 
aquatic animals are still rare and unclear. Therefore, it is necessary to increase the research on the regulatory mechanism of $L$. japonica extract on intestinal health especially the protective effects of $L$. japonica extract on oxidative injury, inflammation, and regulation of intestinal flora in farm and aquatic animals in the future, so as to provide a theoretical basis for the application of $L$. japonica extract in animal production.

\section{AUTHOR CONTRIBUTIONS}

$\mathrm{XT}$ and RF advocated to writing this review, and reviewed, edited, and approved its final version. XT collected literature and wrote the manuscript. XL and JZ helped to collect and review literatures. All authors contributed to the article and approved the submitted version.

\section{REFERENCES}

Alam, A., and Neish, A. (2018). Role of gut microbiota in intestinal wound healing and barrier function. Tissue Barriers 6:e1539595. doi: 10.1080/21688370.2018.1539595

Almenier, H. A., Menshawy, H. H. A., Maher, M. M., and Gamal, S. A. (2012). Oxidative stress and inflammatory bowel disease. Front. Biosci. 4, 1335-1344. doi: $10.2741 / 463$

Bang, B. W., Park, D., Kwon, K. S., Lee, D. H., Jang, M. J., Park, S. K., et al. (2019). BST-104, a water extract of Lonicera japonica, has a gastroprotective effect via antioxidant and anti-inflammatory activities. J. Med. Food 22, 140-151. doi: 10.1089/jmf.2018.4231

Barton, M. D. (2014). Impact of antibiotic use in the swine industry. Curr. Opin. Microbiol. 19, 9-15. doi: 10.1016/j.mib.2014.05.017

Beaumont, M., Paës, C., Mussard, E., Knudsen, C., Cauquil, L., Aymard, P., et al. (2020). Gut microbiota derived metabolites contribute to intestinal barrier maturation at the suckling-to-weaning transition. Gut Microbes 11, 1268-1286. doi: 10.1080/19490976.2020.1747335

Boskabady, M. H., Mehrjardi, S. S., Rezaee, A., Rafatpanah, H., and Jalali, S. (2013). The impact of Zataria multiflora Boiss extract on in vitro and in vivo Th1/Th2 cytokine (IFN- $\gamma /$ IL4) balance. J. Ethnopharmacol. 15, 1024-1031. doi: $10.1016 /$ j.jep.2013.10.003

Bouladoux, N., Harrison, O. J., and Belkaid, Y. (2017). The mouse model of infection with Citrobacter rodentium. Curr. Protoc. Immunol. 119, 19.15.1-19.15.25. doi: 10.1002/cpim.34

Cai, H., Cao, G., Li, L., Liu, X., Ma, X. Q., Tu, S. C., et al. (2013). Profiling and characterization of volatile components from non-fumigated and sulfurfumigated Flos Lonicerae Japonica using comprehensive two-dimensional gas chromatography time-of-flight mass spectrometry coupled with chemical group separation. Molecules 18, 1368-1382. doi: 10.3390/molecules 18021368

Cai, Z., Wang, C., Chen, C., Zou, L., Chai, C., Chen, J., et al. (2021). Quality evaluation of Lonicerae Japonica Flos and Lonicerae Flos based on simultaneous determination of multiple bioactive constituents combined with multivariate statistical analysis. Phytochem. Anal. 32, 129-140. doi: 10.1002/pca.2882

Cai, Z., Wang, C., Zou, L., Liu, X., Chen, J., Tan, M., et al. (2019). Comparison of multiple bioactive constituents in the flower and the caulis of Lonicera japonica based on UFLC-QTRAP-MS/MS combined with multivariate statistical analysis. Molecules 24:1936. doi: 10.3390/molecules24101936

Campbell, J. M., Crenshaw, J. D., and Polo, J. (2013). The biological stress of early weaned piglets. Anim. Sci. Biotechnol. 4:19. doi: 10.1186/2049-1891-4-19

Cao, S., Wu, H., Wang, C., Zhang, Q., Jiao, L., Lin, F., et al. (2018). Diquatinduced oxidative stress increases intestinal permeability, impairs mitochondrial function, and triggers mitophagy in piglets. J. Anim. Sci. 96, 1795-1805. doi: 10.1093/jas/sky104

Chang, W. C., and Hsu, F. L. (1992). Inhibition of platelet activation and endothelial cell injury by polyphenolic compounds isolated from Lonicera

\section{FUNDING}

This research was funded by grants from the World Top Discipline Program of Guizhou Province (No. 1252019 Qianjiao Keyan Fa), the China Overseas Expertise Introduction Program for Discipline Innovation (No. D17016), the Natural Science Research Project of Education Department of Guizhou Province [Qianjiaohe KY Zi (2021) 294], and the Doctoral Launched Scientifc Research Program of Guizhou Normal University [GZNUD (2018) 26].

\section{ACKNOWLEDGMENTS}

We thank Kangning Xiong from the State Engineering Technology Institute for Karst Desertfication Control (Guiyang, China) for his financial support and paper revision.

japonica Thunb. Prostaglandins Leukot. Essent. Fat. Acids 45, 307-312. doi: 10.1016/0952-3278(92)90088-Z

Chaowuttikul, C., Palanuvej, C., and Ruangrungsi, N. (2017). Pharmacognostic specification, chlorogenic acid content, and in vitro antioxidant activities of Lonicera japonica flowering bud. Pharm. Res. 9, 128-132. doi: 10.4103/pr.pr_117_16

Chen, F., Chen, J., Chen, Q., Yang, L., Yin, J., Li, Y., et al. (2021). Lactobacillus delbrueckii protected intestinal integrity, alleviated intestinal oxidative damage, and activated toll-like receptor-bruton's tyrosine kinase-nuclear factor erythroid 2-related factor 2 pathway in weaned piglets challenged with lipopolysaccharide. Antioxidants 10:468. doi: 10.3390/antiox10030468

Chen, X., Lin, H. Z., Jiang, S. G., Wu, K. C., Liu, Y. J., Tian, L. X., et al. (2013). Dietary supplementation of honeysuckle improves the growth, survival and immunity of Penaeus monodon. Fish Shellfish Immunol. 35, 161-169. doi: 10.1016/j.fsi.2013.04.020

Chen, L., Liu, C. S., Chen, Q. Z., Wang, S., Xiong, Y. A., Jing, J., et al. (2017a) Characterization, pharmacokinetics and tissue distribution of chlorogenic acid-loaded self-microemulsifying drug delivery system. Eur. J. Pharm. Sci. 100, 102-108. doi: 10.1016/j.ejps.2017.01.011

Chen, F., Wang, H., Chen, J., Liu, Y., Wen, W., Li, Y., et al. (2020). Lactobacillus delbrueckii ameliorates intestinal integrity and antioxidant ability in weaned piglets after a lipopolysaccharide challenge. Oxidative Med. Cell. Longev. 2020:6028606. doi: 10.1155/2020/6028606

Chen, L., Xu, Y., Chen, X., Fang, C., Zhao, L., and Chen, F. (2017b). The maturing development of gut microbiota in commercial piglets during the weaning transition. Front. Microbiol. 8:1688. doi: 10.3389/fmicb.2017.01688

Choi, C. W., Jung, H. A., Kang, S. S., and Choi, J. (2007). Antioxidant constituents and a new triterpenoid glycoside from Flos Lonicerae. Arch. Pharm. Res. 30, 1-7. doi: 10.1007/BF02977770

Clavijo, V., and Flórez, M. J. V. (2018). The gastrointestinal microbiome and its association with the control of pathogens in broiler chicken production: a review. Poult. Sci. 97, 1006-1021. doi: 10.3382/ps/pex359

Collins, J. W., Keeney, K. M., Crepin, V. F., Rathinam, V. A. K., Fitzgerald, K. A., Finlay, B. B., et al. (2014). Citrobacter rodentium: infection, inflammation and the microbiota. Nat. Rev. Microbiol. 12, 612-623. doi: 10.1038/nrmicro3315

Curciarello, R., Canziani, K. E., Docena, G. H., and Muglia, C. I. (2019). Contribution of non-immune cells to activation and modulation of the intestinal inflammation. Front. Immunol. 10:647. doi: 10.3389/fimmu.2019.00647

Dautzenberg, M. J., Haverkate, M. R., Bonten, M. J., and Bootsma, M. C. (2016). Epidemic potential of Escherichia coli ST131 and Klebsiella pneumoniae ST258: a systematic review and meta-analysis. BMJ Open 6:e009971. doi: 10.1136/bmjopen-2015-009971

Desvaux, M., Dalmasso, G., Beyrouthy, R., Barnich, N., Delmas, J., and Bonnet, R. (2020). Pathogenicity factors of genomic islands in intestinal and extraintestinal Escherichia coli. Front. Microbiol. 11:2065. doi: 10.3389/fmicb.2020.02065

Dharaneedharan, S., Kim, D. H., Park, O., Jang, Y. H., Balasundaram, C., and Heo, M. S. (2016). Dietary effect of Lonicera japonica on immune expression 
in olive flounder Paralichthys olivaceus, challenged with vibrio anguillarum. Isr. J. Aquacult. Bamidgeh 68:20812. doi: 10.46989/001c.20812

Du, C. Z., Feng, X., and Wang, H. (2015). Analysis of volatile constituents in Lonicera japonica Thunb. from different originals by GC-MS. Agric. Sci. Technol. 5, 1081-1083.

Duan, M. H., Fang, T., Ma, J. F., Shi, Q. L., Peng, Y., Ge, F. H., et al. (2018). Homogenate-assisted high-pressure disruption extraction for determination of phenolic acids in Lonicerae Japonica Flos. J. Chromatogr. B Anal. Technol. Biomed. Life Sci. 1097-1098, 119-127. doi: 10.1016/j.jchromb.2018.07.032

Eun, C. S., Kim, Y. S., Han, D. S., Choi, J. H., Lee, A. R., and Park, Y. K. (2011). Lactobacillus casei prevents impaired barrier function in intestinal epithelial cells. APMIS 119, 49-56. doi: 10.1111/j.1600-0463.2010.02691.x

Fan, Z., Li, L., Bai, X., Zhang, H., Liu, Q., Zhang, H., et al. (2019). Extraction optimization, antioxidant activity, and tyrosinase inhibitory capacity of polyphenols from Lonicera japonica. Food Sci. Nutr. 7, 1786-1794. doi: $10.1002 / \mathrm{fsn} 3.1021$

Fang, H., Qi, X., Li, Y., Yu, X., Xu, D., Liang, C., et al. (2020). De novo transcriptomic analysis of light-induced flavonoid pathway, transcription factors in the flower buds of Lonicera japonica. Trees 34, 267-283. doi: 10.1007/s00468-019-01916-4

Fu, Y., Huang, T., Qu, M., Song, X., Chen, Y., Yang, S., et al. (2016). Effects of honeysuckle extracts on serum hormones and antioxidant indexes of beef cattle under heat stress. Chinese J. Anim. Nutr. 28, 926-931. doi: 10.3969/j. issn.1006-267x.2016.03.035

Gao, Z., Ma, F., Dan, Q., Jin, H., Li, H., Chang, M., et al. (2021). Hepatic transcriptome analyses revealed molecular mechanism of Lonicera japonica extract in relieving heat stress of dairy cows. Chinese J. Anim. Nutr. [Epub ahead of print]

Ge, W., Li, H. B., Fang, H., Yang, B., Huang, W. Z., Xiao, W., et al. (2019). A new dimeric secoiridoids derivative, japonicaside E, from the flower buds of Lonicera japonica. Nat. Prod. Res. 33, 53-58. doi: 10.1080/14786419.2018.1431641

Ge, L. L., Li, J. M., Wan, H. Q., Zhang, K. D., Wu, W. G., Zou, X. T., et al. (2018). Novel flavonoids from Lonicera japonica flower buds and validation of their anti-hepatoma and hepatoprotective activity in vitro studies. Ind. Crop. Prod. 125, 114-122. doi: 10.1016/j.indcrop.2018.08.073

Gheisar, M. M., and Kim, I. H. (2018). Phytobiotics in poultry and swine nutrition-a review. Ital. J. Anim. Sci. 17, 92-99. doi: 10.1080/ 1828051X.2017.1350120

Goto, Y., Panea, C., Nakato, G., Cebula, A., Lee, C., Diez, M. G., et al. (2014). Segmented flamentous bacteria antigens presented by intestinal dendritic cells drive mucosal Th17 cell differentiation. Immunity 40, 594-607. doi: 10.1016/j.immuni.2014.03.005

Guevarra, R. B., Hong, S. H., Cho, J. H., Kim, B. R., Shin, J., Lee, J. H., et al. (2018). The dynamics of the piglet gut microbiome during the weaning transition in association with health and nutrition. J. Anim. Sci. Biotechnol. 9:54. doi: 10.1186/s40104-018-0269-6

Guo, A. L., Chen, L. M., Wang, Y. M., Liu, X. Q., Zhang, Q. W., Gao, H. M., et al. (2014). Influence of sulfur fumigation on the chemical constituents and antioxidant activity of buds of Lonicera japonica. Molecules 2014, 16640-16655. doi: 10.3390/molecules191016640

Han, M. H., Lee, W. S., Nagappan, A., Hong, S. H., Jung, J. H., Park, C., et al. (2016). Flavonoids isolated from flowers of Lonicera japonica Thunb. inhibit inflammatory responses in BV2 microglial cells by suppressing TNF- $\alpha$ and IL- $\beta$ through PI3K/Akt/NF-kb signaling pathways. Phytother. Res. 30, 1824-1832. doi: $10.1002 /$ ptr.5688

Hanczakowska, E., Świątkiewicz, M., and Grela, E. R. (2015). Effect of dietary inclusion of a herbal extract mixture and different oils on pig performance and meat quality. Meat Sci. 108, 61-66. doi: 10.1016/j.meatsci.2015.05.020

Hashemi, S. R., and Davoodi, H. (2011). Herbal plants and their derivatives as growth and health promoters in animal nutrition. Vet. Res. Commun. 35, 169-180. doi: 10.1007/s11259-010-9458-2

Hayashi, A., Nagao-Kitamoto, H., Kitamoto, S., Kim, C. H., and Kamada, N. (2021). The butyrate-producing bacterium Clostridium butyricum suppresses Clostridioides difficile infection via neutrophil- and antimicrobial cytokinedependent but GPR43/109a-independent mechanisms. J. Immunol. 206, 1576-1585. doi: $10.4049 /$ jimmunol.2000353

Horai, R., Sen, H. N., and Caspi, R. R. (2017). Commensal microbiota as a potential trigger of autoimmune uveitis. Expert Review Clin. Immu. 13, 291-293. doi: 10.1080/1744666X.2017.1288098
Hou, N., Liu, N., Han, J., Yan, Y., and Li, J. (2017). Chlorogenic acid induces reactive oxygen species generation and inhibits the viability of human colon cancer cells. Anti-Cancer Drugs 28, 59-65. doi: 10.1097/CAD.0000000000000430

Hsu, H. F., Hsiao, P. C., Kuo, T. C., Chiang, S. T., Chen, S. L., Chiou, S. J., et al. (2016). Antioxidant and anti-inflammatory activities of Lonicera japonica Thunb. Var. sempervillosa Hayata flower bud extracts prepared by water, ethanol and supercritical fluid extraction techniques. Ind. Crop. Prod. 89, 543-549. doi: 10.1016/j.indcrop.2016.05.010

Hu, R., He, Z., Liu, M., Tan, J., Zhang, H., Hou, D. X., et al. (2020). Dietary protocatechuic acid ameliorates inflammation and up-regulates intestinal tight junction proteins by modulating gut microbiota in LPS-challenged piglets. J. Anim. Sci. Biotechnol. 11:92. doi: 10.1186/s40104-020-00492-9

Huang, X., Tang, W., and Long, B. (2019). Effects of honeysuckle extract on rumen fermentation, volatile fatty acid composition and gas production in beef cattle. Feed 24, 55-58. doi: 10.15906/j.cnki.cn11-2975/s.20192413

Iwahashi, H., Negoro, Y., Ikeda, A., Morishita, H., and Kido, R. (1986). Inhibition by chlorogenic acid of haematin-catalysed retinoic acid 5,6-epoxidation. Biochem. J. 239, 641-646. doi: 10.1042/bj2390641

Jang, A., Liu, X. D., Shin, M. H., Lee, B. D., Lee, S. K., Lee, J. H., et al. (2008). Antioxidative potential of raw breast meat from broiler chicks fed a dietary medicinal herb extract mix. Poult. Sci. 87, 2382-2389. doi: 10.3382/ ps.2007-00506

Jeong, Y. T., Jeong, S. C., Hwang, J. S., and Kim, J. H. (2015). Modulation effects of sweroside isolated from the Lonicera japonica on melanin synthesis. Chem. Biol. Interact. 238, 33-39. doi: 10.1016/j.cbi.2015.05.022

Jiang, M., Han, Y. Q., Zhou, M. G., Zhao, H. Z., Xiao, X., Hou, Y. Y., et al. (2014). The screening research of anti-inflammatory bioactive markers from different flowering phases of Flos Lonicerae japonica. PLoS One 9:e96214. doi: 10.1371/journal.pone.0096214

Kakuda, R., Imai, M., Yaoita, Y., Machida, K., and Kikuchi, M. (2000). Secoiridoid glycosides fromthe flower buds of Lonicera japonica. Phytochemistry 55, 879-881. doi: 10.1016/s0031-9422(00)00279-x

Kang, O. H., Choi, J. G., Lee, J. H., and Kwon, D. Y. (2010). Luteolin isolated from the flowers of Lonicera japonica suppresses inflammatory mediator release by blocking NF- $\mathrm{KB}$ and MAPKs activation pathways in HMC-1 cells. Molecules 15, 385-398. doi: 10.3390/molecules15010385

Kashiwada, Y., Omichi, Y., Kurimoto, S., Shibata, H., Miyake, Y., Kirimoto, T., et al. (2013). Conjugates of a secoiridoid glucoside with a phenolic glucoside from the flower buds of Lonicera japonica Thunb. Phytochemistry 96, 423-429. doi: $10.1016 /$ j.phytochem.2013.09.021

Kavoosi, G., Tafsiry, A., Ebdam, A. A., and Rowshan, V. (2013). Evaluation of antioxidant and antimicrobial activities of essential oils from Carum copticum seed and Ferula assafoetida latex. J. Food Sci. 78, T356-T361. doi: 10.1111/1750-3841.12020

Kawai, H., Kuroyanagi, M., Umehara, K., Ueno, A., and Satake, M. (1988). Studies on the saponins of Lonicera japonica Thunb. Chem. Pharm. Bull. 36:4769. doi: 10.1248/CРB.36.4769

Kim, S. J., Kim, J. S., Choi, H. S., Kim, Y. M., Hong, S. W., Yeon, S. H., et al. (2015). HS-23, a Lonicera japonica extract, reverses sepsis-induced immunosuppression by inhibiting lymphocyte apoptosis. J. Ethnopharmacol. 171, 231-239. doi: 10.1016/j.jep.2015.05.049

Kim, E. T., Kim, C. H., Min, K. S., and Lee, S. S. (2012). Effects of plant extracts on microbial population, methane emission and ruminal fermentation characteristics in in vitro. Asian-Australs. J. Anim. Sci. 25, 806-811. doi: 10.5713/ajas.2011.11447

Kong, D., Li, Y., Bai, M., Deng, N. Y., Liang, G., and Wu, H. (2017). A comparative study of the dynamic accumulation of polyphenol components and the changes in their antioxidant activities in diploid and tetraploid Lonicera japonica. Plant Physiol. Biochem. 112, 87-96. doi: 10.1016/j. plaphy.2016.12.027

Kumar, N., Singh, B., Bhandari, P., Gupta, A. P., Uniyal, S. K., and Kaul, V. K. (2005). Biflavonoids from Lonicera japonica. Phytochemistry 66, 2740-2744. doi: 10.1016/j.phytochem.2005.10.002

Kuroda, M., Shizume, T., and Mimaki, Y. (2014). Triterpene glycosides from the stems and leaves of Lonicera japonica. Chem. Pharm. Bull. 62, 92-96. doi: $10.1248 /$ cpb.c13-00592

Kwak, W. J., Han, C. K., and Chang, H. W. (2003). Loniceroside C, an antiinflammatory saponin from Lonicera japonica. Chem. Pharm. Bull. 51, 333-433. doi: $10.1248 / \mathrm{cpb} .51 .333$ 
Kwon, S. H., Hong, S. I., Jung, Y. H., Kim, M. J., Kim, S. Y., Kim, H. C., et al. (2012). Lonicera japonica THUNB. protects 6-hydroxydopamine-induced neurotoxicity by inhibiting activation of MAPKs, PI3K/Akt, and NF- $\mathrm{KB}$ in SH-SY5Y cells. Food Chem. Toxicol. 50, 797-807. doi: 10.1016/j.fct.2011.12.026

Lee, E. J., Kim, J. S., Kim, H. P., Lee, J. H., and Kang, S. S. (2010). Phenolic constituents from the flower buds of Lonicera japonica and their 5-lipoxygenase inhibitory activities. Food Chem. 120, 134-139. doi: 10.1016/j. foodchem.2009.09.088

Lee, J., Park, G., and Chang, Y. H. (2019). Nutraceuticals and antioxidant properties of Lonicera japonica Thunb. as affected by heating time. Int. J. Food Prop. 22, 630-645. doi: 10.1080/10942912.2019.1599389

Lee, S. J., Shin, E. J., Son, K. H., Chang, H. W., Kang, S. S., and Kim, H. P. (1995). Anti-inflammatory activity of the major constituents of Lonicera japonica. Arch. Pharm. Res. 18, 133-135. doi: 10.1007/BF02979147

Lee, K. H., Whang, K. S., and Rhee, K. H. (2011). Effects of Lonicera japonica Thunb. on dextran sulfate sodium-induced experimental colitis in mice. J. Med. Plant Res. 5, 5437-5443. doi: 10.1002/cbic.201100354

Lei, X. J., Yun, H. M., and Kim, I. H. (2018). Effects of dietary supplementation of natural and fermented herbs on growth performance, nutrient digestibility, blood parameters, meat quality and fatty acid composition in growingfinishing pigs. Ital. J. Anim. Sci. 17, 984-993. doi: 10.1080/1828051X. 2018.1429955

Li, J., and Han, Y. Y. (2020). Research advances on non-flower bud parts of Lonicera japonica Thunb. Chin. Arch. Tradit. Chin. Med. 38, 43-50.

Li, X. Y., He, C., Zhu, Y., and Lu, N. H. (2020). Role of gut microbiota on intestinal barrier function in acute pancreatitis. World J. Gastroenterol. 26, 2187-2193. doi: 10.3748/wjg.v26.i18.2187

Li, R., Kuang, X., Wang, W., Wan, C., and Li, W. (2020). Comparison of chemical constitution and bioactivity among different parts of Lonicera japonica Thunb. J. Sci. Food Agric. 100, 614-622. doi: 10.1002/jsfa.10056

Li, Y., Li, W., Fu, C., Song, Y., and Fu, Q. (2019). Lonicerae japonica flos and Lonicerae flos: a systematic review of ethnopharmacology, phytochemistry and pharmacology. Phytochem. Rev. 22, 1-61. doi: 10.1007/s11101-019-09655-7

Li, H. B., Yu, Y., Mei, Y. D., Meng, Z. Q., Wang, Z. Z., Huang, W. Z., et al. (2017). A new hetero dimeric terpenoid derivative, japonicaside C, from the flower buds of Lonicera japonica. Nat. Prod. Res. 31, 143-148. doi: 10.1080/14786419.2016.1219859

Lin, Z. N., Ye, L., Li, Z. W., Huang, X. S., Lu, Z., Yang, Y. Q., et al. (2020). Chinese herb feed additives improved the growth performance, meat quality, and nutrient digestibility parameters of pigs. Animal Model Exp. Med. 3, 47-54. doi: 10.1002/ame2.12104

Lin, L. M., Zhang, X. G., Zhu, J. J., Gao, H. M., Wang, Z. M., and Wang, W. H. (2008). Two new triterpenoid saponins from the flowers and buds of Lonicera japonica. J. Asian Nat. Prod. Res. 10, 925-929. doi: 10.1080/10286020802217366

Liu, P., Bai, X., Zhang, T., Zhou, L., Li, J., and Zhang, L. (2019). The protective effect of Lonicera japonica polysaccharide on mice with depression by inhibiting NLRP3 inflammasome. Ann. Transl. Med. 7:811. doi: 10.21037/ atm.2019.12.64

Liu, Z. X., Cheng, Z. Y., He, Q. J., Lin, B., Gao, P. Y., Li, L. Z., et al. (2016). Secondary metabolites from the flower buds of Lonicera japonica and their in vitro anti-diabetic activities. Fitoterapia 110, 44-51. doi: 10.1016/j. fitote.2016.02.011

Liu, W., and Kim, I. H. (2017). Influence of extract mixture from Scutellaria baicalensis and Lonicera japonica on egg production, nutrient digestibility, blood profiles and egg quality in laying hens reared in hot humid season. Anim. Nutr. Feed. Technol. 17, 137-146. doi: 10.5958/ 0974-181X.2017.00014.2

Liu, Z. X., Liu, C. T., Liu, Q. B., Ren, J., and Song, S. J. (2015). Iridoid glycosides from the flower buds of Lonicera japonica and their nitric oxide production and $\alpha$-glucosidase inhibitory activities. J. Funct. Foods 18, 512-519. doi: $10.1016 /$ j.jff.2015.08.017

Liu, W., Pi, S. H., and Kim, I. H. (2016). Effects of Scutellaria baicalensis and Lonicera japonica extract mixture supplementation on growth performance, nutrient digestibility, blood profiles and meat quality in finishing pigs. Ital. J. Anim. Sci. 15, 446-452. doi: 10.1080/1828051x.2016.1202736

Liu, T., Yang, J., Liu, S., Zhao, Y., Zhou, J., Jin, Y., et al. (2020). Regulation of chlorogenic acid, flavonoid, and iridoid biosynthesis by histone H3K4 and H3K9 methylation in Lonicera japonica. Mol. Biol. Rep. 47, 9301-9311. doi: $10.1007 /$ s11033-020-05990-7
Liu, S., You, L., Zhao, Y., and Chang, X. (2018). Wild Lonicera caerulea berry polyphenol extract reduces cholesterol accumulation and enhances antioxidant capacity in vitro and in vivo. Food Res. Int. 107, 73-83. doi: 10.1016/j. foodres.2018.02.016

Long, B., Li, Z., Dong, G., Wang, Q., and Yu, Z. (2018). Effects of honeysuckle extract on performance, egg quality, lipid metabolism and yolk cholesterol content of laying hens. Chinese J. Anim. Nutr. 30, 212-218. doi: 10.3969/j. issn.1006-267x.2018.01.026

Looft, T., Allen, H. K., Cantarel, B. L., Levine, U. Y., Bayles, D. O., Alt, D. P., et al. (2014). Bacteria, phages and pigs: the effects of in-feed antibiotics on the microbiome at different gut locations. ISME J. 8:1566. doi: 10.1038/ ismej.2014.12

Lum, H., and Roebuck, K. A. (2001). Oxidant stress and endothelial cell dysfunction. Am. J. Phys. Cell Physiol. 280, C719-C741. doi: 10.1152/ ajpcell.2001.280.4.C719

Luo, L., Zhang, B., Ma, L., Fan, J., Zhu, W., Guan, N., et al. (2018). Antioxidant activity in vitro and protective effect of flavonoids from Lonicera japonica Thunb. leaves on $\mathrm{H}_{2} \mathrm{O}_{2}$-induced toxicity in RAW264.7 cells. Food Sci. 39, 139-145. doi: 10.7506/spkx1002-6630-201811022

Ma, F. T., Shan, Q., Jin, Y. H., Gao, D., Li, H. Y., Chang, M. N., et al. (2020a). Effect of Lonicera japonica extract on lactation performance, antioxidant status, and endocrine and immune function in heat-stressed mid-lactation dairy cows. J. Dairy Sci. 103, 10074-10082. doi: 10.3168/ jds.2020-18504

Ma, F. T., Shan, Q., Jin, Y. H., Li, H. Y., Gao, D., and Sun, P. (2020b). Effects of Lonicera japonica extract on performance, serum biochemical indexes and immune function of heat-stressed dairy cows. Chinese J. Anim. Nutr. 32, 2209-2217. doi: 10.3969/j.issn.1006-267x.2020.05.030

Makki, K., Deehan, E. C., Walter, J., and Bäckhed, F. (2018). The impact of dietary fiber on gut microbiota in host health and disease. Cell Host Microbe 23, 705-715. doi: 10.1016/j.chom.2018.05.012

Meng, X. L., Zhu, Z. X., Lu, R. H., Li, S., Hu, W. P., Qin, C. B., et al. (2019). Regulation of growth performance and lipid metabolism in juvenile grass carp (Ctenopharyngodon idella) with honeysuckle (Lonicera japonica) extract. Fish Physiol. Biochem. 45, 1563-1573. doi: 10.1007/s10695-019-00644-3

Miao, H., Zhang, Y., Huang, Z., Lu, B., and Ji, L. (2019). Lonicera japonica attenuates carbon tetrachloride-induced liver fibrosis in mice: molecular mechanisms of action. Am. J. Chin. Med. 47, 351-367. doi: 10.1142/ S0192415X19500174

Minami, M., and Makino, T. (2020). Effects of Lonicera japonica flower bud extract on citrobacter rodentium-induced digestive tract infection. Medicine 7:52. doi: $10.3390 /$ medicines7090052

Miner-Williams, W. M., and Moughan, P. J. (2016). Intestinal barrier dysfunction: implications for chronic inflammatory conditions of the bowel. Nutr. Res. Rev. 29, 40-59. doi: 10.1017/S0954422416000019

Mullineaux-Sanders, C., Sanchez-Garrido, J., Hopkins, E. G. D., Shenoy, A. R., Barry, R., and Frankel, G. (2019). Citrobacter rodentium-host-microbiota interactions: immunity, bioenergetics and metabolism. Nat. Rev. Microbiol. 17, 701-705. doi: 10.1038/s41579-019-0252-Z

Müştak, H. K., Torun, E., Özen, D., Yücel, G., Akan, M., and Diker, K. S. (2015). Effect of Lonicera japonica extract on mycoplasma gallisepticum in naturally infected broiler flocks. Br. Poult. Sci. 56, 299-303. doi: 10.1080/00071668.2015.1022711

Navarro-Yepes, J., Burns, M., Anandhan, A., Khalimonchuk, O., del Razo, L. M., Quintanilla-Vega, B., et al. (2014). Oxidative stress, redox signaling, and autophagy: cell death versus survival. Antioxid. Redox Signal. 21, 66-85. doi: $10.1089 /$ ars.2014.5837

Park, J. H., Kang, S. N., Chu, G. M., and Jin, S. K. (2014). Growth performance, blood cell profiles, and meat quality properties of broilers fed with Saposhnikovia divaricata, Lonicera japonica, and Chelidonium majus extracts. Livest. Sci. 165, 87-94. doi: 10.1016/j.livsci.2014.04.014

Park, K. I., Kang, S. R., Park, H. S., Lee, D. H., Nagappan, A., Kim, J. A., et al. (2012). Regulation of proinflammatory mediators via NF- $\kappa B$ and $\mathrm{p} 38$ MAPK-dependent mechanisms in RAW 264.7 macrophages by polyphenol components isolated from Korea Lonicera japonica THUNB. Evid. Based Complement. Alternat. Med. 2012:828521. doi: 10.1155/2012/828521

Peng, P., Deng, D., Chen, S. J., Li, C. L., Luo, J., Romeo, A., et al. (2020). The effects of dietary porous zinc oxide supplementation on growth performance, inflammatory cytokines and tight junction's gene expression 
in early-weaned piglets. J. Nutr. Sci. Vitaminol. 66, 311-318. doi: 10.3177/ jnsv.66.311

Peng, L. Y., Mei, S. X., Jiang, B., Zhou, H., and Sun, H. D. (2000). Constituents from Lonicera japonica. Fitoterapia 71, 713-715. doi: 10.1016/ S0367-326X(00)00212-4

Qamar, A., Waheed, J., Hamza, A., Mohyuddin, S. G., Lu, Z., Namula, Z., et al. (2021). The role of intestinal microbiota in chicken health, intestinal physiology and immunity. J. Anim. Plant Sci. 31, 342-351. doi: 10.36899/ JAPS.2021.2.0221

Qi, L. W., Chen, C. Y., and Li, P. (2009). Structural characterization and identification of iridoid glycosides, saponins, phenolic acids and flavonoids in Flos Lonicerae Japonica by a fast liquid chromatography method with diode-array detection and time-of-flight mass spectrometry. Rapid Commun. Mass Spectrom. 23, 3227-3242. doi: 10.1002/rcm.4245

Qiu, S., Bai, M., Zhao, P., Liu, Z. X., Huang, X. X., and Song, S. J. (2021). Phytochemical and network-based chemotaxonomic study of Lonicera japonica thunb. Biochem. Syst. Ecol. 94:104210. doi: 10.1016/j.bse.2020.104210

Rauter, A. P., Ennis, M., Hellwich, K. H., Herold, B. J., Horton, D., Moss, G. P., et al. (2018). Nomenclature of flavonoids (IUPAC recommendations 2017). Pure Appl. Chem. 90, 1429-1486. doi: 10.1515/pac-2013-0919

Rhee, K. H., and Lee, K. H. (2011). Antimicrobial effects of Lonicera japonica against gram positive and gram negative anaerobic bacteria. Nat. Prod. Sci. $17,23-25$.

Salerno-Goncalves, R., Safavie, F., Fasano, A., and Sztein, M. B. (2016). Free and complexed-secretory immunoglobulin A triggers distinct intestinal epithelial cell responses. Clin. Exp. Immunol. 185, 338-347. doi: 10.1111/ cei. 12801

Saracila, M., Panaite, T. D., Papuc, C. P., and Criste, R. D. (2021). Heat stress in broiler chickens and the effect of dietary polyphenols, with special reference to willow (Salix spp.) bark supplements-a review. Antioxidants 10:686. doi: 10.3390/antiox10050686

Seo, O. N., Kim, G. S., Park, S., Lee, J. H., Kim, Y. H., Lee, W. S., et al. (2012). Determination of polyphenol components of Lonicera japonica thunb. Using liquid chromatography-tandem mass spectrometry: contribution to the overall antioxidant activity. Food Chem. 134, 572-577. doi: 10.1016/j. foodchem.2012.02.124

Shang, X., Pan, H., Li, M., Miao, X., and Ding, H. (2011). Lonicera japonica Thunb. ethnopharmacology, phytochemistry and pharmacology of an important traditional Chinese medicine. J. Ethnopharmacol. 138, 1-21. doi: 10.1016/j. jep.2011.08.016

Shi, Z., Liu, Z., Liu, C., Wu, M., Su, H., Ma, X., et al. (2016). Spectrum-effect relationships between chemical fingerprints and antibacterial effects of Lonicerae Japonica Flos and Lonicerae Flos base on UPLC and microcalorimetry. Front. Pharmacol. 7:12. doi: 10.3389/fphar.2016.00012

Sicard, J. F., Le Bihan, G., Vogeleer, P., Jacques, M., and Harel, J. (2017). Interactions of intestinal bacteria with components of the intestinal mucus. Front. Cell. Infect. Microbiol. 7:387. doi: 10.3389/fcimb.2017.00387

Son, K. H., Jung, K. Y., Chang, H. W., Kim, H. P., and Kang, S. S. (1994). Triterpenoid saponins from the aerial parts of Lonicera japonica. Phytochemistry 35, 1005-1008. doi: 10.1016/S0031-9422(00)90656-3

Song, X., Fu, Y., Huang, T., Qu, M., Chen, Y., Yang, S., et al. (2015). Effects of honeysuckle extract on antioxidant function and skeletal muscle morphology of beef cattle under hot environment. Chinese J. Anim. Nutr. 27, 3534-3540. doi: 10.3969/j.issn.1006-267x.2015.11.026

Song, W., Li, S., Wang, S., Wu, Y., Zi, J., Gan, M., et al. (2008). Pyridinium alkaloid-coupled secoiridoids from the flower buds of Lonicera japonica. J. Nat. Prod. 71, 922-925. doi: 10.1021/np800040k

Stromberg, Z. R., Johnson, J. R., Fairbrother, J. M., Kilbourne, J., Van Goor, A., Curtiss Rd, R., et al. (2017). Evaluation of Escherichia coli isolates from healthy chickens to determine their potential risk to poultry and human health. PLoS One 12:e0180599. doi: 10.1371/journal.pone. 0180599

Su, X., Zhu, Z. H., Zhang, L., Wang, Q., Xu, M. M., Lu, C., et al. (2021). Anti-inflammatory property and functional substances of Lonicerae Japonica caulis. J. Ethnopharmacol. 267:113502. doi: 10.1016/j.jep.2020.113502

Surin, S., Surayot, U., Seesuriyachan, P., You, S. G., and Phimolsiripol, Y. (2018). Antioxidant and immunomodulatory activities of sulphated polysaccharides from purple glutinous rice bran (Oryza sativa L.). Int. J. Food Sci. Technol. 53, 994-1004. doi: 10.1111/ijfs.13674
Tan, C., Ling, Z., Huang, Y., Cao, Y., Liu, Q., Cai, T., et al. (2015). Dysbiosis of intestinal microbiota associated with inflammation involved in the progression of acute pancreatitis. Pancreas 44, 868-875. doi: 10.1097/ MPA.0000000000000355

Tang, X. P., Fang, R. J., Pan, G. C., and Xiong, K. N. (2019). Acute effect of epidermal growth factor on phosphate diffusion across intestinal mucosa of hens using the ussing chamber system. Pak. J. Zool. 51, 2209-2216. doi: 10.17582/journal.pjz/2019.51.6.2209.2216

Tang, Z., Jiang, L., Yang, L., Sun, F., and Xiong, B. (2018a). Effects of honeysuckle extract on rumen in vitro fermentation parameters and gas production. Chinese J. Anim. Nutr. 30, 790-796. doi: 10.3969/j/issn.1006-267x.2018.02.045

Tang, X. P., Liu, X. G., and Liu, H. (2021). Mechanisms of epidermal growth factor effect on animal intestinal phosphate absorption: a review. Front. Vet. Sci. 8:670140. doi: 10.3389/fvets.2021.670140

Tang, X. P., Liu, B., Wang, X. R., Yu, Q. F., and Fang, R. J. (2018b). Epidermal growth factor, through alleviating oxidative stress, protect IPEC-J2 cells from lipopolysaccharides-induced apoptosis. Int. J. Mol. Sci. 19:848. doi: 10.3390/ ijms 19030848

Tang, X. P., Liu, H., Yang, S. F., Li, Z. H., Zhong, J. F., and Fang, R. J. (2016). Epidermal growth factor and intestinal barrier function. Mediat. Inflamm. 2016:1927348. doi: 10.1155/2016/1927348

Tang, X. P., and Xiong, K. N. (2021). Effects of epidermal growth factor on glutamine and glucose absorption by IPEC-J2 cells challenged by lipopolysaccharide using the Ussing chamber system. Pak. J. Zool. 53, 417-422. doi: 10.17582/journal.pjz/20200117080156

Tzeng, T. F., Liou, S. S., Chang, C. J., and Liu, I. M. (2014). The ethanol extract of Lonicera japonica (Japanese honeysuckle) attenuates diabetic nephropathy by inhibiting p-38 MAPK activity in streptozotocin-induced diabetic rats. Planta Med. 80, 121-129. doi: 10.1055/s-0033-1360196

Villena, J., Chiba, E., Vizoso-Pinto, M. G., Tomosada, Y., Takahashi, T., Ishizuka, T., et al. (2014). Immunobiotic lactobacillus rhamnosus strains differentially modulate antiviral immune response in porcine intestinal epithelial and antigen presenting cells. BMC Microbiol. 14:126. doi: 10.1186/1471-2180-14-126

Vukovic, N., Kacaniova, M., Hleba, L., and Sukdolak, S. (2012). Chemical composition of the essential oils from the flower, leaf and stem of Lonicera japonica. Nat. Prod. Commun. 7, 641-644.

Wan, H., Ge, L., Li, J., Zhang, K., Wu, W., Peng, S., et al. (2019). Effects of a novel biflavonoid of Lonicera japonica flower buds on modulating apoptosis under different oxidative conditions in hepatoma cells. Phytomedicine 57, 282-291. doi: 10.1016/j.phymed.2018.12.044

Wan, M. L. Y., Ling, K. H., El-Nezami, H., and Wang, M. F. (2019). Influence of functional food components on gut health. Crit. Rev. Food Sci. Nutr. 59, 1927-1936. doi: 10.1080/10408398.2018.1433629

Wang, J. H., Bose, S., Kim, G. C., Hong, S. U., Kim, J. H., Kim, J. E., et al. (2014). Flos Lonicera ameliorates obesity and associated endotoxemia in rats through modulation of gut permeability and intestinal microbiota. PLoS One 9:e86117. doi: 10.3389/fmicb.2018.01953

Wang, Y., Chen, Y., Zhang, X., Lu, Y., and Chen, H. (2020). New insights in intestinal oxidative stress damage and the health intervention effects of nutrients: a review. J. Funct. Foods 75:104248. doi: 10.1016/j.jff.2020.104248

Wang, M., Huang, H., Hu, Y., Liu, Y., Zeng, X., Zhuang, Y., et al. (2020). Effects of dietary supplementation with herbal extract mixture on growth performance, organ weight and intestinal morphology in weaning piglets. J. Anim. Physiol. Anim. Nutr. 104, 1462-1470. doi: 10.1111/jpn.13422

Wang, J., Ji, H., Wang, S., Liu, H., Zhang, W., Zhang, D., et al. (2018). Probiotic lactobacillus plantarum promotes intestinal barrier function by strengthening the epithelium and modulating gut microbiota. Front. Microbiol. 9:1953. doi: $10.3389 /$ fmicb.2018.01953

Wang, L., Jiang, Q., Hu, J., Zhang, Y., and Li, J. (2016). Research progress on chemical constituents of Lonicerae japonica flos. Biomed. Res. Int. 2016:8968940. doi: $10.1155 / 2016 / 8968940$

Wang, H., Li, Y., Wang, S., Kong, D., Sahu, S. K., Bai, M., et al. (2020). Comparative transcriptomic analyses of chlorogenic acid and luteolosides biosynthesis pathways at different flowering stages of diploid and tetraploid Lonicera japonica. Peer J. 8:e8690. doi: 10.7717/peerj.8690

Wang, F., Miao, M., Xia, H., Yang, L. G., Wang, S. K., and Sun, G. J. (2016). Antioxidant activities of aqueous extracts from 12 Chinese edible flowers in vitro and in vivo. Food Nutr. Res. 61:1265324. doi: 10.1080/ 16546628.2017 .1265324 
Wang, C., Wang, G., Liu, H., and Hou, Y. L. (2016). Protective effect of bioactive compounds from Lonicera japonica Thunb. against $\mathrm{H}_{2} \mathrm{O}_{2}$-induced cytotoxicity using neonatal rat cardiomyocytes. Iran. J. Basic Med. Sci. 19, 97-105.

Wang, D. Y., Zhao, X. M., and Liu, Y. L. (2017). Hypoglycemic and hypolipidemic effects of a polysaccharide from flower buds of Lonicera japonica in streptozotocin-induced diabetic rats. Int. J. Biol. Macromol. 102, 396-404. doi: 10.1016/j.ijbiomac.2017.04.056

Windisch, W., Schedle, K., Plitzner, C., and Kroismayr, A. (2008). Use of phytogenic products as feed additives for swine and poultry. J. Anim. Sci. 86, E140-E148. doi: 10.2527/jas.2007-0459

Wu, S., Yano, S., Chen, J., Hisanaga, A., Sakao, K., He, X., et al. (2017). Polyphenols from Lonicera caerulea L. berry inhibit LPS-induced inflammation through dual modulation of inflammatory and antioxidant mediators. J. Agric. Food Chem. 65, 5133-5141. doi: 10.1021/acs.jafc.7b01599

Xiao, L., Liang, S., Ge, L., Wan, H., Wu, W., Fei, J., et al. (2020). 4,5-di-Ocaffeoylquinic acid methyl ester isolated from Lonicera japonica Thunb. targets the Keap1/Nrf2 pathway to attenuate H2O2-induced liver oxidative damage in HepG2 cells. Phytomedicine 70:153219. doi: 10.1016/j. phymed.2020.153219

Xiong, J., Li, S., Wang, W., Hong, Y., Tang, K., and Luo, Q. (2013). Screening and identification of the antibacterial bioactive compounds from Lonicera japonica Thunb. leaves. Food Chem. 138, 327-333. doi: 10.1016/j. foodchem.2012.10.127

Xu, X., Yan, G., Chang, J., Wang, P., Yin, Q., Liu, C., et al. (2020). Astilbin ameliorates deoxynivalenol-induced oxidative stress and apoptosis in intestinal porcine epithelial cells (IPEC-J2). J. Appl. Toxicol. 40, 1362-1372. doi: 10.1002/ jat.3989

Yan, L., Xie, Y., Wang, Y., Zhu, J., Li, M., Liu, X., et al. (2020). Variation in contents of active components and antibacterial activity in different parts of Lonicera japonica thunb. Asian Biomed. 14, 19-26. doi: 10.1515/ abm-2020-0004

Yan, Z., Zhong, Y., Duan, Y., Chen, Q., and Li, F. (2020). Antioxidant mechanism of tea polyphenols and its impact on health benefits. Anim. Nutr. 6, 115-123. doi: 10.1016/j.aninu.2020.01.001

Yang, L., Aguilar, Z. P., Qu, F., Xu, H., Xu, H., and Wei, H. (2016). Enhanced antimicrobial activity of silver nanoparticles-Lonicera japonica Thunb combo. IET Nanobiotechnol. 10, 28-32. doi: 10.1049/iet-nbt.2015.0027

Yang, R., Hao, H., Li, J., Xuan, J., Xia, M. F., and Zhang, Y. Q. (2020). Three new secoiridoid glycosides from the flower buds of Lonicera japonica. Chin. J. Nat. Med. 18, 70-74. doi: 10.1016/S1875-5364(20)30006-6

Yang, J., Li, Y. C., Zhou, X. R., Xu, X. J., Fu, Q. Y., and Liu, C. Z. (2018). Two thymol derivatives from the flower buds of Lonicera japonica and their antibacterial activity. Nat. Prod. Res. 32, 2238-2243. doi: 10.1080/14786419.2017.1371153

Yang, F., Wang, A., Zeng, X., Hou, C., Liu, H., and Qiao, S. (2015). Lactobacillus reuteri $\mathrm{I} 5007$ modulates tight junction protein expression in IPEC-J2 cells with LPS stimulation and in newborn piglets under normal conditions. BMC Microbiol. 15:32. doi: 10.1186/s12866-015-0372-1

Yang, X., Zhang, F., Xiang, F., Dai, Z., Yu, C., and Li, S. (2020). Honeysuckle extract promotes host health by improving intestinal microbes and enhancing intestinal mucosal immunity. Genom. Appl. Biol. 39, 1257-1263. doi: 10.13417/j. gab.039.001257

Yejun, L., Su Kyoung, L., Shin Ja, L., Jong-Su, E., and Sung Sill, L. (2019). Effects of Lonicera japonica extract supplementation on in vitro ruminal fermentation, methane emission, and microbial population. Anim. Sci. J. 90, 1170-1176. doi: 10.1111/asj.13259

Yin, J., Wu, M. M., Xiao, H., Ren, W. K., Duan, J. L., Yang, G., et al. (2014). Development of an antioxidant system after early weaning in piglets. J. Anim. Sci. 92, 612-619. doi: 10.2527/jas.2013-6986

Yitbarek, A., Astill, J., Hodgins, D. C., Parkinson, J., Nagy, É., and Sharif, S. (2019). Commensal gut microbiota can modulate adaptive immune responses in chickens vaccinated with whole inactivated avian influenza virus subtype H9N2. Vaccine 37, 6640-6647. doi: 10.1016/j.vaccine.2019.09.046

Yoo, H. J., Kang, H. J., Song, Y. S., Park, E. H., and Lim, C. J. (2008). Antiangiogenic, antinociceptive and anti-inflammatory activities of Lonicera japonica extract. J. Pharm. Pharmacol. 60, 779-786. doi: 10.1211/jpp.60.6.0014

Yu, Y., Jiang, Z., Song, W., Yang, Y., Li, Y., Jiang, J., et al. (2015). Glucosylated caffeoylquinic acid derivatives from the flower buds of Lonicera japonica. Acta Pharm. Sin. B 5, 210-214. doi: 10.1016/j.apsb.2015.01.012
Yu, Y., Song, W., Zhu, C., Lin, S., Zhao, F., Wu, X., et al. (2011). Homosecoiridoids from the flower buds of Lonicera japonica. J. Nat. Prod. 74, 2151-2160. doi: $10.1021 / \mathrm{np} 2004566$

Yu, Y., Zhu, C., Wang, S., Song, W., Yang, Y., and Shi, J. (2013). Homosecoiridoid alkaloids with amino acid units from the flower buds of Lonicera japonica. J. Nat. Prod. 76, 2226-2233. doi: 10.1021/np4005773

Zhang, T., Liu, H., Bai, X., Liu, P., Yang, Y., Huang, J., et al. (2020). Fractionation and antioxidant activities of the water-soluble polysaccharides from Lonicera japonica Thunb. Int. J. Biol. Macromol. 151, 1058-1066. doi: 10.1016/j. ijbiomac.2019.10.147

Zhang, X., Zhao, Q., Ci, X., Chen, S., Xie, Z., Li, H., et al. (2020). Evaluation of the efficacy of chlorogenic acid in reducing small intestine injury, oxidative stress, and inflammation in chickens challenged with Clostridium perfringens type A. Poult. Sci. 99, 6606-6618. doi: 10.1016/j.psj.2020.09.082

Zhao, Y., Dou, D., Guo, Y., Qi, Y., Li, J., and Jia, D. (2018). Comparison of the trace elements and active components of Lonicera japonica flos and Lonicera flos using ICP-MS and HPLC-PDA. Biol. Trace Elem. Res. 183, 379-388. doi: 10.1007/s12011-017-1138-4

Zhao, Y., Tang, Z., Nan, X., Sun, F., Jiang, L., and Xiong, B. (2020). Effects of Lonicera japonica extract on performance, blood biomarkers of inflammation and oxidative stress during perinatal period in dairy cows. Asian-Australas. J. Anim. Sci. 33, 1096-1102. doi: 10.5713/ajas.19.0388

Zheng, Z. F., Zhang, Q. J., Chen, R. Y., and Yu, D. Q. (2012). Four new $\mathrm{N}$-contained iridoid glycosides from flower buds of Lonicera japonica. J. Asian Nat. Prod. Res. 14, 729-737. doi: 10.1080/10286020.2012.688038

Zhou, X., Dong, Q., Kan, X., Peng, L., Xu, X., Fang, Y., et al. (2018a). Immunomodulatory activity of a novel polysaccharide from Lonicera japonica in immunosuppressed mice induced by cyclophosphamide. PLoS One 13:e0204152. doi: 10.1371/journal.pone.0204152

Zhou, X., He, G., Ma, J., Tang, M., Tian, G., Gong, X., et al. (2020). Protective effect of a novel polysaccharide from Lonicera japonica on cardiomyocytes of mice injured by hydrogen peroxide. Biomed. Res. Int. 2020:5279193. doi: $10.1155 / 2020 / 5279193$

Zhou, X., Lu, Q., Kang, X., Tian, G., Ming, D., and Yang, J. (2021). Protective role of a new polysaccharide extracted from Lonicera japonica Thunb in mice with ulcerative colitis induced by dextran sulphate sodium. Biomed. Res. Int. 2021:8878633. doi: 10.1155/2021/8878633

Zhou, X., Zhang, Y., Wu, X., Wan, D., and Yin, Y. (2018b). Effects of dietary serine supplementation on intestinal integrity, inflammation and oxidative status in early-weaned piglets. Cell. Physiol. Biochem. 48, 993-1002. doi: $10.1159 / 000491967$

Zhu, H., Wang, H., Wang, S., Tu, Z., Zhang, L., Wang, X., et al. (2018). Flaxeed oil attenuates intestinal damage and inflammation by regulating necroptosis and TLR4/NOD signaling pathways following lipopolysaccharide challenge in a piglet model. Mol. Nutr. Food Res. 62:e1700814. doi: 10.1002/ mnfr.201700814

Zhu, L., Zhang, D., Zhu, H., Zhu, J., Weng, S., Dong, L., et al. (2018). Berberine treatment increases Akkermansia in the gut and improves high-fat dietinduced atherosclerosis in Apoe-/- mice. Atherosclerosis 268, 117-126. doi: 10.1016/j.atherosclerosis.2017.11.023

Conflict of Interest: The authors declare that the research was conducted in the absence of any commercial or financial relationships that could be construed as a potential conflict of interest.

Publisher's Note: All claims expressed in this article are solely those of the authors and do not necessarily represent those of their affiliated organizations, or those of the publisher, the editors and the reviewers. Any product that may be evaluated in this article, or claim that may be made by its manufacturer, is not guaranteed or endorsed by the publisher.

Copyright (c) 2021 Tang, Liu, Zhong and Fang. This is an open-access article distributed under the terms of the Creative Commons Attribution License (CC BY). The use, distribution or reproduction in other forums is permitted, provided the original author(s) and the copyright owner(s) are credited and that the original publication in this journal is cited, in accordance with accepted academic practice. No use, distribution or reproduction is permitted which does not comply with these terms. 